\title{
A framework for constructing and evaluating the role of $M R$ as a holographic virtual guide in museums
}

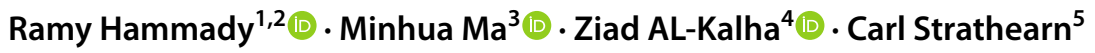

Received: 6 July 2020 / Accepted: 7 December 2020

(c) The Author(s), under exclusive licence to Springer-Verlag London Ltd. part of Springer Nature 2021

\begin{abstract}
Mixed reality (MR) is a cutting-edge technology at the forefront of many new applications in the tourism and cultural heritage sector. This study aims to reshape the museum experience by creating a highly engaging and immersive museum experience for visitors combing real-time visual, audio information and computer-generated images with museum artefacts and customer displays. This research introduces a theoretical framework that assesses the potential of MR guidance system in usefulness, ease of use, enjoyment, interactivity, touring and future applications. The evaluation introduces the MuseumEye MR application in the Egyptian Museum, Cairo using mixed method surveys and a sample of 171 participants. The results of the questionnaire highlighted the importance of the mediating the role of the tour guide in enhancing the relationship between perceived usefulness, ease of use, multimedia, UI design, interactivity and the intention of use. Furthermore, the results of this study revealed the potential future use of MR in museums and ensured sustainability and engagement past the traditional visitor museum experience, which heightens the economic state of museums and cultural heritage sectors.
\end{abstract}

Keywords Mixed reality $\cdot$ Virtual guide $\cdot$ Museums $\cdot$ Holographic system $\cdot$ Microsoft HoloLens

\section{Introduction}

Supplementary Information The online version of this article (https://doi.org/10.1007/s10055-020-00497-9) contains supplementary material, which is available to authorized users.

Ramy Hammady

Ramy.Hammady@solent.ac.uk;

Ramy_Hammady@a-arts.helwan.edu.eg

Minhua Ma

m.ma@falmouth.ac.uk

Ziad AL-Kalha

Z.kalha@ju.edu.jo

Carl Strathearn

C.strathearn@napier.ac.uk

1 Solent University, E Park Terrace, Southampton SO14 0YN, UK

2 Helwan University, Al Sikka Al Hadid Al Gharbeya, Al Masaken Al Iqtisadeyah, Helwan, Cairo Governorate, Egypt

3 Falmouth University, Penryn Campus, Treliever Road, Penryn TR10 9FE, UK

4 University of Jordan, School of Business, Queen Rania Street, Amman, Jordan

5 Edinburgh Napier University, Unit 4, 10 Bankhead Terrace, Edinburgh EH11 4DY, UK
With the advent of virtual reality (VR) and augmented reality (AR) in the cultural heritage domain over the last two decades (Fenu and Pittarello 2018; Schaper et al. 2018; Sylaiou et al. 2010). These technologies have enhanced the visitor experience and reshaped the traditional physical borders with the creation of innovative windows into the past, present and future (Trunfio et al. 2020). The application of AR in museums enhances and visualises essential visitor information and increase interaction with other technologies and multimedia elements (Antlej et al. 2018). Moreover, AR technologies propagate longer exhibit and display interactions and instigate greater visceral learning than the typical museum experience (Pujol et al. 2012).

Significantly, virtual museum guides enhance engagement and social interaction between visitors (Kopp et al. 2005). These virtual guides can increase the attendance and attention of museum visitors (Burgard et al. 1999; Rzayev et al. 2019) and increase the economic state of tourism as a vital source of income (Rosentraub and Joo 2009). Typically, museums employ communication systems that include senders, receivers and channels of communication which facilitate the transmission of verbal and non-verbal information 
to the visitor (Cameron 1968; Munodawafa 2008). However, museums employ such systems to relay information and content indirectly, which often results in visitors missing essential information (Knez and Wright 1970).

Therefore, the use of guiding roles such as 'Mentor' and 'Pathfinder' received a considerable amount of attention in museums and cultural heritage sites (Best 2012; Cohen 1985; Zhang and Chow 2004). As a result, many studies refocused on the role of the tour guide and how to educate visitors (Best 2012; Hooper-Greenhill 1999; Horn 1980; Mancini 2000; Pond 1993; Zhang and Chow 2004). For instance, Best (2012), concluded that museum visitors prefer the AR guides to enhance the education experience. Therefore, fulfilling the visitors' needs, the evolution of the virtual guidance is classified in two components:

(a) VR systems that guide visitor by reimaging exhibits (Zuk et al. 2005), support and provide customer navigation (Boland and Johnson 1996). Owen et al. (2005), and immerse visitors with holographical content (Kateros et al. 2015). Moreover, mobile VR devices enhance museum guidance by adding relevant directions, information and content using the visitor's location (Damala et al. 2008; Rekimoto and Ayatsuka 2000; Sparacino 2002). The success of VR touring systems in museums has extended their application to outdoor cultural heritage site with guided services that integrate navigation, information and location with 2D and 3D images, audio and video clips to personalise the visitor experience (Madsen and Madsen 2015; Vlahakis et al. 2002).

(b) The second stage of VR/AR progression in museums moved towards interactive head-worn devices with eyetracking capabilities that provide greater accessibility and immersion with content than mobile phone and tablet devices (Wagner 2007; Sparacino 2002; Damala and Stojanovic 2012). Other smart immersive technological guide systems were created based on the visitors' content co-creation and personalisation (Antón et al. 2018; Ardito et al. 2018).

Flavián et al. (2019) conducted a study on human factors in AR, which suggests AR HCI emulates the highest levels of natural human communication. Furthermore, in a museum setting, AR interactions increase the guiding functions, which enhance the interaction between visitors and the artefacts (Ng Giap Weng et al. 2011; Trunfio et al. 2020) and in some instances employ gesture control for natural HCI (Burgard et al. 1999). In addition, the gamification of AR guidance systems in museums increases visitor engagement and promotes active learning (Raptis et al. 2017). However, this research found that current AR museum guides were not aligned with the role of human guides such as being mentor, pathfinder, educator, information-giver and motivator (Cohen 1985; Holloway 1981; Weiler and Black 2015). Most studies in this area consider AR technologies as a set of tools that support the guiding experience in museums and neglect the significance of interactivity, multimedia, user interface design and usefulness in the context of the museum experience. Moreover, recent studies do not address the influences of interactivity, multimedia and user interface design and usefulness on the effectiveness of the role of guidance in MR guide tools.

Thus, this study identifies a gap in current MR HCI research and explores the role of MR as a smart immersive technology to redesign the traditional museum tour guide service. In consideration, this research study designed, tested and deployed a novel spatial MR guide system called 'MuseumEye' in the Egyptian Museum in Cairo to investigate; interactivity, multimedia, user interface design, intention and usefulness of the MR tour guide system. The system was built using the Microsoft MR HoloLens and took 9 months to create and deploy, including testing and fixing bugs.

\section{Background and related work}

\subsection{Guidance in museums}

Museums are multidimensional environments and require a multi-perspective approach to guidance enhanced by implementing technologies such as AR, VR and MR (Raptis et al. 2018). However, the most significant roles that museums play are in attracting people and enriching their knowledge (Doering and Pekarik 1996). A museum guide is defined as verbal or non-verbal instructions and information that helps visitors to engage, amuse, educate and navigate (Best 2012; Fine and Speer 1985). Many studies focus on visitors and the aspects of communication and interactions taking place (Duffy 1989; Hodge et al. 1979; Hooper-Greenhill 2013; Yalowitz and Bronnenkant 2009). These studies reveal that the structure of guided tours provides information that the guide can follow to foster the audiences' contributions and engagements. However, applying models of best practice are significant for interpretation services and intercultural communication (Weiler and Black 2015). Many studies emphasise the role of the tour guide in educating museum visitors (Hooper-Greenhill 1999; Horn 1980; Mancini 2000; Pond 1993).

For instance, Cohen (1985) explains that the modern tour guide has to fulfil the role of a' pathfinder', to lead visitors around the museum environment. Secondly, the tour guide is a' mentor', who provides visitors with essential information (Cohen 1985). Furthermore, museum mentoring is a social interaction in face-to-face settings (Goodwin 2007). For example, Best (2012) advocated 'Museum guides use 
pointing and gaze at objects, as the group move to orient themselves and others to new foci'. Thus, the mentoring role involves being a 'social mediation' and 'cultural brokerage' (Cohen 1985; Holloway 1981).

There are other essential guide roles such as the 'actor' to reenact information to the audience, the 'Information-giver' to exchange and impart knowledge, the 'Ambassador' as a representative of the heritage's culture and country and the 'Catalyst' to encourage social cohesion in touristic groups (Holloway 1981). Moreover, tour guides are 'Leaders' as they show the way around the museum and act as the social leader of the tourist group (Cohen 1985). Finally, they are the 'Teacher' and 'caretaker' as they inform tourists about the souvenirs they can buy (Fine and Speer 1985). 'Interpreter/translator' (Almagor 1985) and 'organiser' (Hughes 1991).

\subsection{Virtual, augmented and mixed realities in museums}

With the advent of the new technologies and devices which produce multiple realities, it is significant to redefine the difference between AR and VR systems in the MR (MR) spectrum. In consideration, Bray (2018) proposed a new taxonomy of MR, as depicted in Fig. 1.

The technology present in AR devices expanded the application of VR thanks to advances in sensors and control, which amalgamate and minimise the gap between the physical environment and virtual spectrum. Holographic devices, such as Microsoft HoloLens 1.0 (Microsoft 2015), Microsoft HoloLens 2.0 (Microsoft 2019), Magic Leap (Magic Leap 2018) and Meta 2 (Prasuethsut 2016), have the ability to place virtual content in the physical environment (Bray 2018). Conversely, VR devices construct a sense of presence by replacing the physical environment with virtual content (Bray 2018). Examples VR devices include the Oculus Rift (Rift 2020), Acer headset (Warren 2018), ASUS headset (Allison 2018), and Dell Visor (Atkinson 2018).
Jaron Lanier created the term 'Virtual Reality' in 1980s, and it was described as "a human computer interface that simulates realistic environment while enabling participant interaction, as a 3D digital world that accurately models actual environments, or simply as cyberspace" (Gorman et al. 2000, p. 124). On the other side, AR is now sees as "Augmented reality is a medium in which information is added to the physical world in registration with the world" (Craig 2013, p. 15). However, MR is an inclusive term which can embrace the two different worlds; the virtual world and the real-world which differ in their nature (Milgram et al. 1995). The two terms AR and MR are used interchangeably in the literature, especially in studies that involve holograms observed by Microsoft HoloLens. For instance, the term AR is used in studies that employ the Microsoft HoloLens system (Hockett and Ingleby 2016) and MR to describe the same device (Hurter and McDuff 2017; Kress and Cummings 2017). Furthermore, extended reality (XR) is a new term which arose recently to include AR, VR and MR under one umbrella. Moreover, XR represents a broad variety of virtuality levels to increase the level of immersion by all types of sensor inputs. This term included AR, VR and MR under one umbrella (Alizadehsalehi et al. 2020).

Many studies in different disciplines adopted these immersive technologies and it was found that it can result a significant impact in the needed outcomes. XR technologies showed an obvious potential in the architecture, engineering and construction industry particularly on the efficiency of designing (Alizadehsalehi et al. 2019), building (Sampaio and Martins 2014), operating and monitoring phases (Alizadehsalehi et al. 2020; Rahimian et al. 2020). In the medical sector, hybrid worlds create the experience for immersive e-therapy (Gorini et al. 2008). MR helped to save lives (Siebert et al. 2017), and MR glasses were efficient in forensic science (Albrecht et al. 2013). XR technologies are very promising in the medical health field as they have a significant effectiveness on the medical training and education and can increase the level of diagnosis and treatments (John and

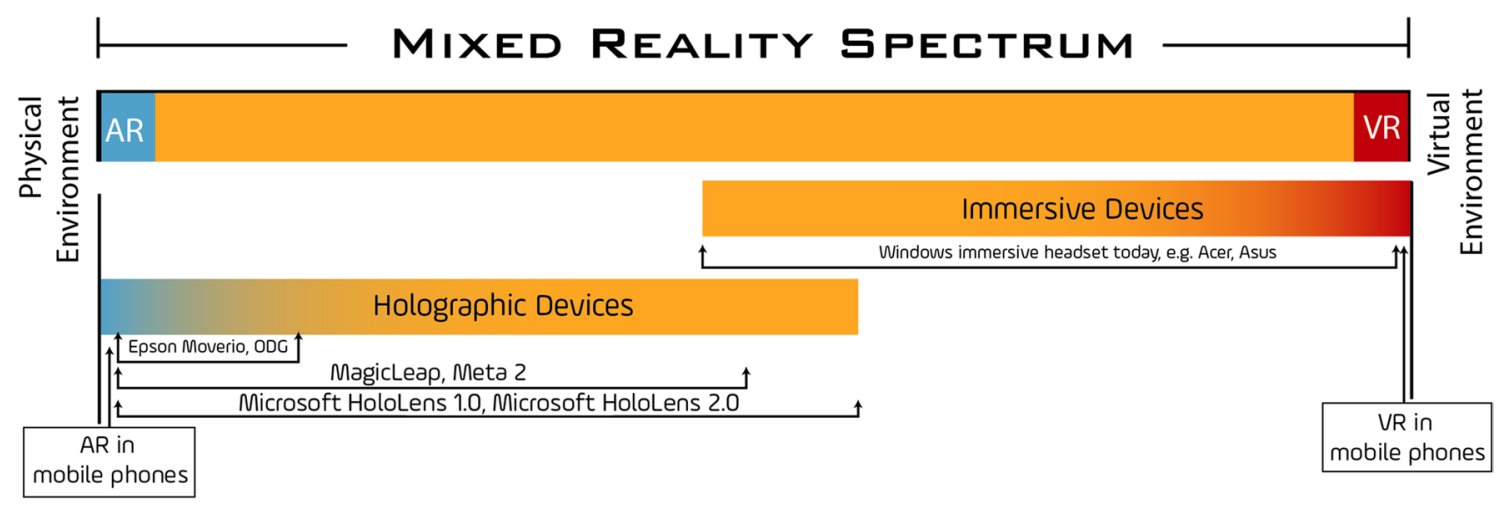

Fig. 1 MR spectrum concept developed from Bray (2018) and the allocation of holographic and immersive devices 
Wickramasinghe 2020). In the education sector, VR and MR technologies revealed a significant effectiveness on enhancing the learning attitude for secondary students; moreover, MR was proved to be better than traditional teaching methods (Tang et al. 2020).

Recently in the cultural heritage sector, many museums have implemented AR and VR, MR technologies to take over and substitute the roles of human guides to navigate and providing visual and auditory information to guests on the spot. In the last decade, the installation of AR, VR and MR on mobile and wearable devices permit users to navigate museum environments naturally without significant restriction. The social presence of these technologies was interpreted by Jung et al. (2016) into four classifications: educational, aesthetics, entertainment and escape experiences. Hence, the following literature demonstrates how immersive technologies fulfil visitor needs in museums and cultural heritage places.

According to Brůha et al. (2020), Clini et al. (2017) and Hain and Hajtmanek (2019), VR systems allow museum visitors to interact, navigate, explore virtual reconstructions of lost heritage. Thus, VR is one of the most appealing and interactive technologies to emerge in the museum sector (Lee et al. 2020; Mihelj et al. 2014) and in virtual museums (Fevgas et al. 2014; Guerra et al. 2015; Loizides et al. 2014; Sylaiou et al. 2019). However, Carrozzino and Bergamasco (2010) argue that it is uncommon and costly to equip museums with immersive VR installations and Zuk et al. (2005), explain that VR is more suited to visualise temporal 3D archaeological data and gaming approaches for educating and entertaining visitors (Antoniou et al. 2019; Lepouras 2004). VR technologies can virtually reconstruct and rebuild a ruined heritage to provide visitors with an insight into the past (Cantatore et al. 2020; Pujol 2004).

However, VR systems do not support mobility features, which is a critical role of the museum tour guide. Accordingly, researchers developed a portable AR tour guide (Damala et al. 2008) to provide real-time routing tailored to the visitors' position in the museum (Van Hage et al. 2010). Subsequent studies deployed mobile AR headsets in the Louvre museum's Department of Islamic Art for guidance and information provision (Miyashita et al. 2008). Another interactive $A R$ installation allowed visitors to change the colour of paintings (Ryffel et al. 2017). Similar studies examined the use of personalised storytelling alongside artefacts (Muñoz and Martí 2020; Pujol et al. 2012; Roussou et al. 2013) and overlying information via AR (Keil et al. 2013; Sugiura et al. 2019; Xu et al. 2012) across different platforms, such as smartphones, tablets and smart glasses (Pietroszek et al. 2019; Serubugo et al. 2017).

Thus, MR technologies have contributed towards enhancing the visitor experience in the museum and cultural heritage sector. For example, one AR project extends the exhibition space with virtual visualisation of ancient sea life (Hughes et al. 2004) and the 'HoloMuse' MR application engages users with archaeological artefacts through gesturebased interactions (Pollalis et al. 2017; Wang and Xia 2019). Another MR project enabled an immersive interactive experience to explore the potential of MR in museums (Cortana 2017). Gesture recognition techniques were applied to an MR guide system by a smartphone application to gather user facial expression data (Lee et al. 2017) and create a virtual character for HCI (Avramova et al. 2017; Raptis et al. 2018). MR technology has transformed the way humans interact with each other as the immersive technologies can transcend physical barriers (Kim et al. 2020; Sylaiou et al. 2018) as self-guided tools to ease learning (Bekele et al. 2018) and increase the perception and enhance the real-world (Choi 2014; Vo et al. 2019).

Moreover, MR technology needs to be tailored to visitors' needs and expectations (Weiler and Black 2015) and should be aligned to the museum guide roles (tom Dieck et al. 2016). According to Falk and Dierking (2016), there are three overlapping contexts that constitute the museum experience and interpret the museum visitor needs personal context, sociocultural context and the physical context. Therefore, this research attempts to redefine the role of the museum guide and provide visitors with a self-guided, immersive, engaging and educational experience.

\section{MuseumEye-an MR tour guide}

The MR application 'MuseumEye' developed in this study proves the potential of MR guidance by giving museum visitors a glimpse of what it was like to live in ancient Egypt. Adding virtual characters and objects overlaid with music and sound effects created an interacting and engaging MR experience. MuseumEye introduces a virtual guide who speaks to the visitor and provides various types of visual information such as videos, images and 3D visualisations of artefacts. The advantage of 3D virtual rendered objects over physical artefacts is that visitors get a closer and unrestricted look at exhibits outside of the glass case and observe objects from different angles. The MR application emulates ten antiques from the Tutankhamun exhibit with three storytelling scenes. The MR avatar guide walks alongside the museum visitor from the very start of the tour and the experience lasts between 30 and $40 \mathrm{~min}$.

\subsection{Structure of the MR guide model}

The MR guide system was designed after considering the three main contexts that constitute the museum experience defined by Falk and Dierking (2016), in addition to the defined roles of tour guides introduced by Cohen 
(1985), Holloway (1981) and Fine and Speer (1985). The roles of the tour guide and visitor needs were analysed and linked to museum experience constructs from a side and connected to conceptual functions from the other side as demonstrated in Fig. 2. These functions were mapped and bridged to technical operations that can be achieved using the MR device. This systematic approach prioritises the main roles of the guiding service delivered by humans, machines, tools or gadgets and ensures that the concepts that fed to the structure of the system not vice versa.

The application incorporates a game named "Knowledge Scale game" that encourages visitors to discover hidden secrets and clues in the virtual relics. To further engage the visitor, the system has a historical MR avatar with corresponding scenes and to engage visitors in the ancient Egyptian Era. The utilisation of 3D images, text, 3D virtual antiques, holographic floating UI with hand interactions-as depicted in Fig. 3-and spatial sound effects provided visitors with essential information on the spot. The system implements' voice commands' to personalise HCI, this function makes the system communicative and responsive to questions, assigned tasks and to convey the sense of being led by a trusted programme to ensure the maximum engagement and entertainment. Furthermore, the system is designed to engage multiple users simultaneously in a collaborative shared experience for sustainability and ease of usage.

\subsection{The concept of the interactions in MR guides}

The system provided five levels of interaction, depicted in Fig. 4. Firstly, the visitor in front of the exhibited item will interact with the physical environment. Secondly, interacting with the physical item. Thirdly, interacting with the virtual guide and watching his demonstrations and facial expressions. Fourthly, interaction and manipulation of the virtual artefact. Fifthly, with the UI which include buttons and triggers (Hammady 2019). Thus, the more interactions the visitors perform, the information they receive. This interactive environment raises the level of concentration and knowledge consumption for museum visitors and motivates the visitors' cognitive ability, which reflects on the impression that visitors can feel at the end of the tour. The UI has a set of buttons, one for showing related images, another for showing the script that the guide narrates from and another for the guide surrounded by floating relics. There are further buttons for going between scenes and quitting the app.

\subsection{Hardware}

The MR HMD Microsoft HoloLens-depicted in Fig. 5utilised in this research is a wearable computer system and implements the Intel 32-bit (1 GHz) processor, accelerometer, gyroscope and magnetometer. It is also equipped with 2 GB RAM and battery for 2-3 $\mathrm{h}$ of active use and Windows 10 (Microsoft 2015).

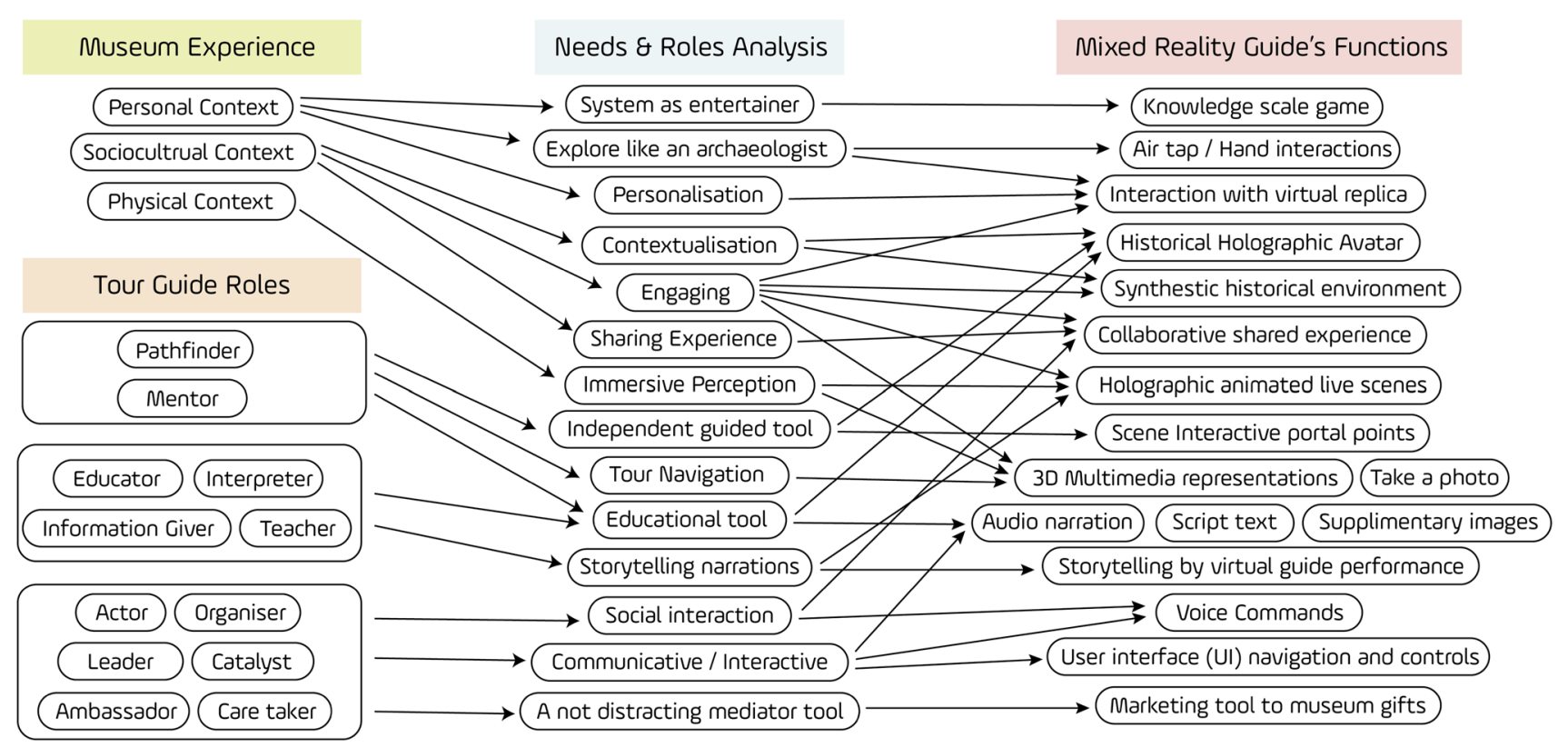

Fig. 2 Bridging museum guide roles and visitor needs to MuseumEye functions 


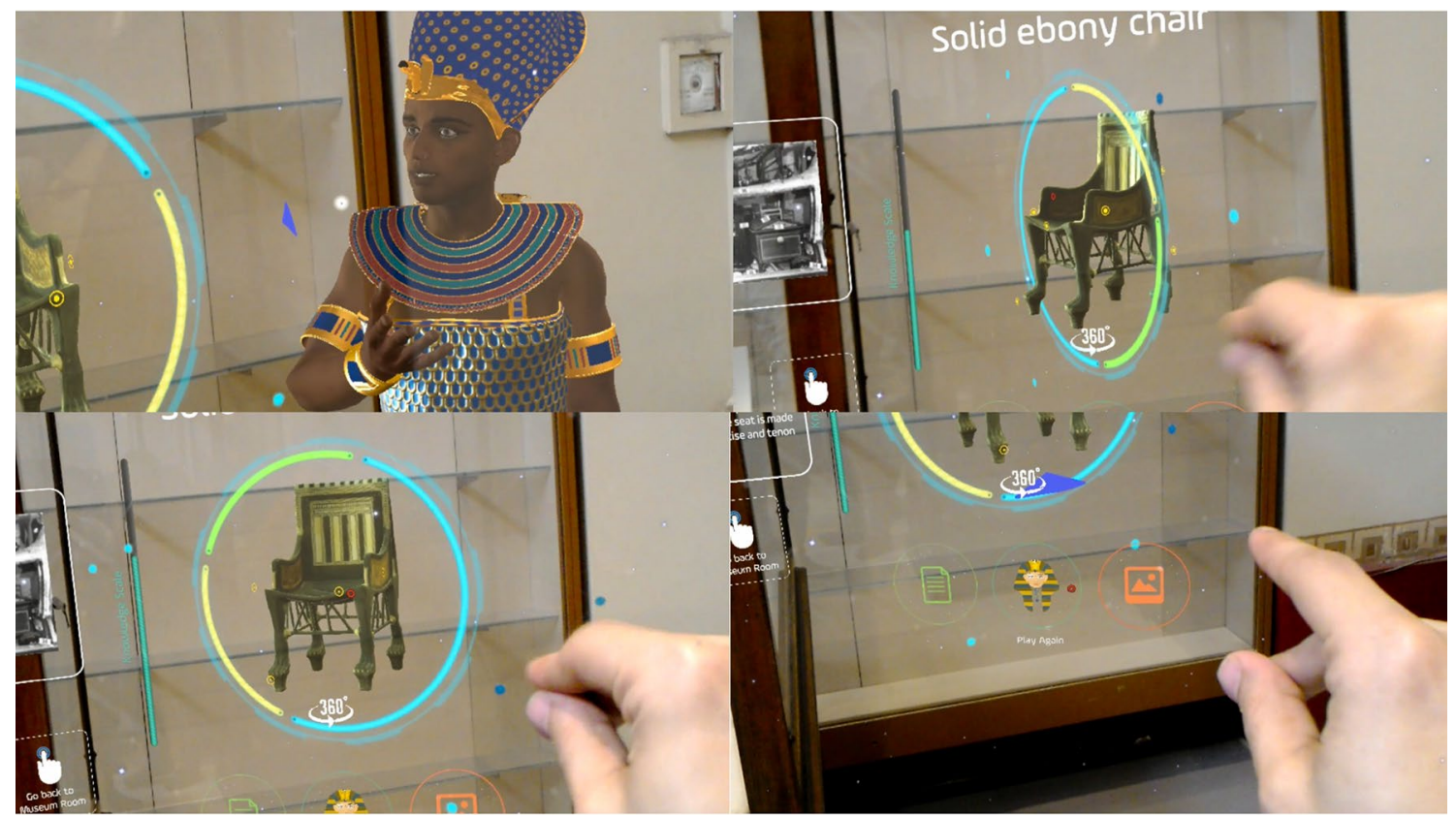

Fig. 3 Floating UI of MuseumEye with hand interactions

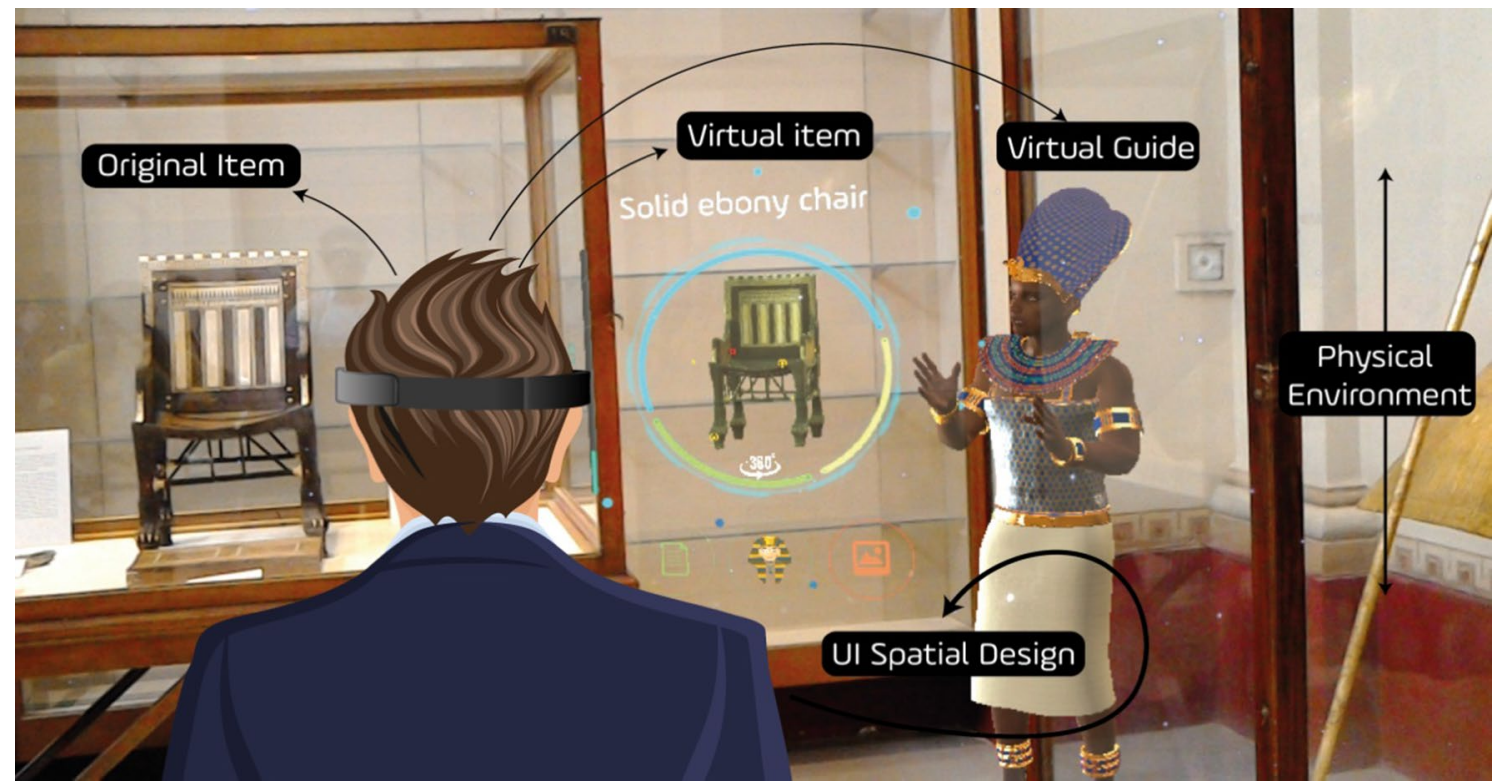

Fig. 4 MuseumEye - the MR virtual guide system and levels of interaction

\section{Research method}

Technology acceptance model (TAM) introduced by Davis (1989) is a theory of reasoned action (TRA) that suggests that human's behaviour is determined by a person's intention to perform a certain behaviour (Ajzen and Fishbein 1980; Fishbein and Ajzen 1975). This perceptual intention is a function of a person's attitude and behaviour from the subjective norm. As the attitude towards a certain behaviour can propagate positive or negative feelings, the subjective norms can evaluate the social pressure on the person either to do or not to do the behaviour. For many years, TAM has been used to measure the adoption of new technologies by users in information technology (IT) and immersive technologies in museums. For example, 


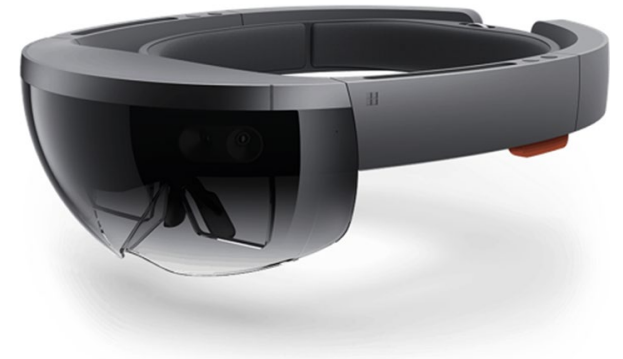

Fig. 5 Microsoft HoloLens. Source: Microsoft (2015)

the TAM model investigates public acceptance of MR (Rauschnabel and Ro 2016) or the applicability in different disciplines such as MR in education (Rasimah et al. 2011) and the role of the AR guide in museums (Haugstvedt and Krogstie 2012).

As presented in Fig. 6, the basic TAM model by Davis (1989) shows the usage of IT manifested by intention, determined by the user's attitude towards acceptance. According to the TAM model, the perceived usefulness and the perceived ease of use are the predictors of the users' acceptability. Moreover, the perceived usefulness and the perceived ease of use can be influenced by several external variables. However, there are five constructs of TAM; for the purpose of this research attitude towards using IT was excluded. Previous studies demonstrate a direct relationship between the intention to use and the actual usage without connecting them with the attitude towards using IT (Ducey and Coovert 2016; Shang and Wu 2017). Many TAM researchers extend the model using additional external constructs or external stimulus. For instance, Ayeh et al. (2013) emphasised on the significance of using context-specific external constructs within TAM study model to ensure the suitability within different technological contexts.

Numerous studies explore the understudy variables with museums/locations and the technology involved, as presented in Table 1. The table encompasses the literature of the previous system that was applied and evaluated in museums in terms of indicating the aspects that were measured. Although some technologies in the literature were different from HoloLens, these aspects still needed to be explored for a comprehensive evaluation.

\section{The proposed model and hypotheses}

This section develops the hypotheses based on the literature review in order to develop a theoretical explanatory model as depicted in Fig. 7. This theoretical model integrates the social and technical constructs of the literature review with the TAM model for exploring the perceived usefulness and perceived ease of use are considered cognitive responses and the intention to use. The technical constructs are represented in interactivity, multimedia and UI. This model involves three interrelated constructs covering, 'the perceived usefulness', 'the perceived ease of use' and 'the intention to use'. In the other side, the constructs 'the perceived enjoyment' and 'the role of guide'.

Firstly, this framework investigates the relationships between these variables towards defining the intention to use the MR guide. Secondly, the study investigates a new variable constructed through the literature review, which is the 'Role of Guide'. This construct is explored among the other constructs in relation to the intention to use the system. Finally, this research explores how the role of the guide influences the other constructs in this context to highlight the sustainability of using this system in museums.

\subsection{Perceived usefulness and intention to use}

Usefulness (USF) is one of the fundamental factors to predict user acceptance by measuring the effect of behaviour over usage (Davis 1985, 1989). The perceived usefulness has a significant effect in the intention to use (ITU) AR in museums (Chung et al. 2015; Haugstvedt and Krogstie 2012; Lee et al. 2015). MuseumEye supposes to transfer knowledge and to enrich the contextual information of the exhibit. It also attempts to change the mental image of the ancient Egyptian's civilisation. Usefulness was exploited in many museum studies as a construct to be assessed (Haugstvedt and Krogstie 2012; Hughes et al. 2005; Wojciechowski and Cellary 2013).

Intention to use (ITU) is measured to assess the sustainability of the system in the museum post-experiment. Several museum studies employed this construct (Lee et al. 2015; Wojciechowski and Cellary 2013; Yilmaz 2016).

Fig. 6 TAM model introduced by Davis (1989)

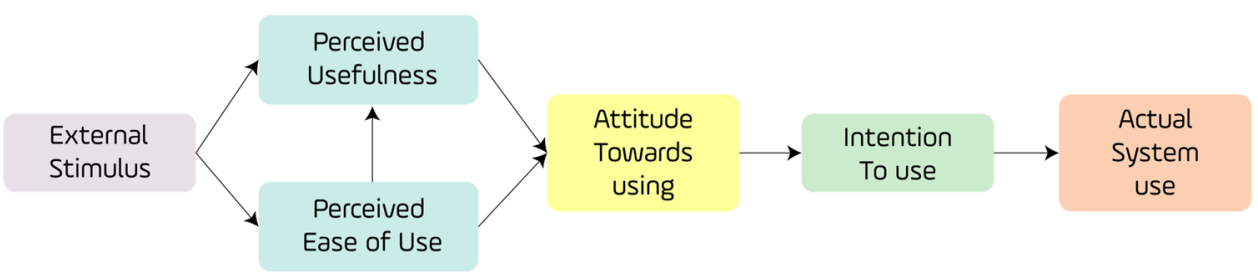


Table 1 The explored constructs in the literature of previous studies

\begin{tabular}{|c|c|c|c|}
\hline Projects/studies & Museum/location & Technology—device & Evaluation aspects \\
\hline Damala et al. (2008) & $\begin{array}{l}\text { Museum of Fine Arts in Rennes, } \\
\text { France }\end{array}$ & AR_mobile device & $\begin{array}{l}\text { Ease of use } \\
\text { Navigation } \\
\text { Content quality: audio and } \\
\text { multimedia }\end{array}$ \\
\hline ARCO (Karoulis et al. 2006) & $\begin{array}{l}\text { Victoria and Albert Museum and } \\
\text { SussexPast, UK }\end{array}$ & $\begin{array}{l}\text { Virtual museum and } \mathrm{AR} \text {-mobile } \\
\text { and website or kiosks }\end{array}$ & $\begin{array}{l}\text { Usability } \\
\text { Content: terminology suitability, } \\
\text { logical order } \\
\text { Reliability } \\
\text { Multimedia }\end{array}$ \\
\hline $\begin{array}{l}\text { ARCHEOGUIDE (Vlahakis et al. } \\
\text { 2001) }\end{array}$ & $\begin{array}{l}\text { The archaeological site of Olym- } \\
\text { pia, Greece }\end{array}$ & $\begin{array}{l}\text { AR-mobile units (laptop, pen- } \\
\text { PC, palmtop-based) }\end{array}$ & $\begin{array}{l}\text { Ease of use } \\
\text { User satisfaction } \\
\text { Multimedia } \\
\text { User interface } \\
\text { Content } \\
\text { The willingness of future use }\end{array}$ \\
\hline $\begin{array}{l}\text { Trondheim historical streets (Haug- } \\
\text { stvedt and Krogstie 2012) }\end{array}$ & $\begin{array}{l}\text { Trondheim historical streets, } \\
\text { Norway }\end{array}$ & $\mathrm{AR}$ —mobile device & $\begin{array}{l}\text { Usefulness } \\
\text { Ease of use } \\
\text { Enjoyment } \\
\text { Behaviour attention }\end{array}$ \\
\hline $\begin{array}{l}\text { Hypermedia tour guide (Bellotti } \\
\text { et al. 2002) }\end{array}$ & $\begin{array}{l}\text { Genoa's Costa Aquarium Museum, } \\
\text { Italy }\end{array}$ & $\begin{array}{l}\text { Handheld guide—palmtop com- } \\
\text { puter }\end{array}$ & $\begin{array}{l}\text { Usability } \\
\text { Information presentation } \\
\text { User satisfaction } \\
\text { Content }\end{array}$ \\
\hline $\begin{array}{l}\text { MR Sea Creatures experience } \\
\text { (Hughes et al. 2005) }\end{array}$ & $\begin{array}{l}\text { The Orlando Science Centre's } \\
\text { DinoDigs exhibition hall, USA }\end{array}$ & $\begin{array}{l}\text { MR experience-see-through } \\
\text { video HMD }\end{array}$ & $\begin{array}{l}\text { User reactions } \\
\text { Usefulness } \\
\text { Enjoyment } \\
\text { The willingness of future use }\end{array}$ \\
\hline Agent Max (Kopp et al. 2005) & The Nixdorf Museum & $\begin{array}{l}\text { AI (artificial inelegance)—flat } \\
\text { screen }\end{array}$ & Interactivity \\
\hline ARCO (Sylaiou et al. 2010) & $\begin{array}{l}\text { Victoria and Albert Museum and } \\
\text { SussexPast, UK }\end{array}$ & $\begin{array}{l}\text { Virtual museum and AR-mobile } \\
\text { and website or kiosks }\end{array}$ & $\begin{array}{l}\text { Enjoyment } \\
\text { Previous computing experience } \\
\text { User satisfaction }\end{array}$ \\
\hline Carrozzino and Bergamasco (2010) & $\begin{array}{l}\text { The Virtual Museum of Sculpture } \\
\text { (VMS) of Pietrasanta }\end{array}$ & Virtual museum—VR gadgets & $\begin{array}{l}\text { Interactivity } \\
\text { Immersion } \\
\text { Content }\end{array}$ \\
\hline
\end{tabular}

H1 Usefulness (USF) has a significant direct relationship with intention to use (ITU) MuseumEye.

People engaged in activities of pleasure and enjoyment (Teo and Lim 1997). Davis et al. (1992) defined enjoyment as "the extent to which the activity of using the technology is perceived to be enjoyable in its own right, apart from any performance consequences that may be anticipated". In this study, MuseumEye brings amusement and pleasure to visitors during the dissemination of information through storytelling and narratives.

Visitors prefer to be active users, not passive listeners, so they prefer to perform interactions as much as possible. Based on the design of MuseumEye guide, the system uses hand gesture control to enhance and personalise the museum tour experience. Hence, the evaluation of this aspect is crucial to the evaluation as if the system is not engaging, it will be neglected by visitors in the future. Enjoyment was measured in many previous museums studies (Hughes et al. 2005; Schmalstieg and Wagner 2007; Sylaiou et al. 2010).

\subsection{Enjoyment}

Empirically, the perceived enjoyment (ENJ) has a significant effect on the intention to use (ITU) as the joyfulness that users can feel after using the MR applications can motivate them to continue using the system in the future. Similar studies can prove this relation (Haugstvedt and Krogstie 2012; 


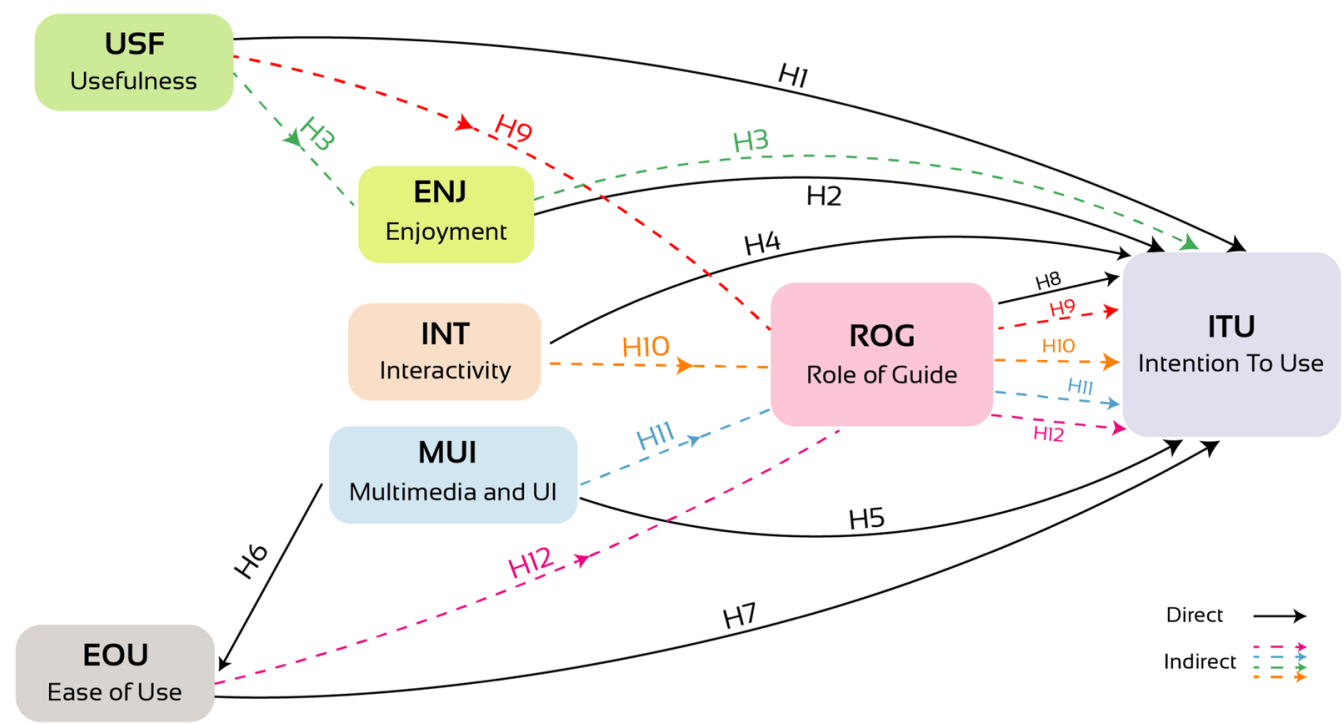

Fig. 7 Proposed theoretical model

Lee et al. 2015; Leue and Jung 2014; Sylaiou et al. 2010; Wojciechowski and Cellary 2013). Also, the perceived usefulness (USF) as an extrinsic motivation construct also has a significant effect on the perceived enjoyment (ENJ) as an extrinsic motivation construct presented in a related study (Koenig-Lewis et al. 2015).

H2 Enjoyment (ENJ) has a significant direct relationship with intention to use (ITU) MuseumEye.

H3 Enjoyment (ENJ) significantly mediates the relationship between usefulness (USF) and intention to use (ITU) MuseumEye.

\subsection{Interactivity}

Interactivity (INT) is defined as "the user capability of modifying the environment and receiving feedback to his/her actions" (Carrozzino and Bergamasco 2010, p. 435). Due to the particular hand gesture that is required to accomplish the interaction in HoloLens, this aspect measures the ability to do the interaction to the designed UI as it is considered a new experience for users to face.

Once users interact with MuseumEye, they can perceive two different types of interactions, HCI and interpersonal interaction. HCI considers the MR system in the museum environment, and interpersonal interaction is a result of the interaction between the visitor and his/her peers. Thus, interaction influences the intention to use (ITU) defined by Liu et al. (2010).

H4 Interactivity (INT) has a significant direct relationship with intention to use (ITU) MuseumEye.

\subsection{Multimedia and UI}

Multimedia and UI are aspects of the content design and comprise video and audio documentaries and informative images (Karoulis et al. 2006). In addition to measuring the aesthetical quality of the UI and content, it was helpful to assist the user in performing actions. Good UI and multimedia content can influence visitors to engage and grasp information towards perceived ease of use (EOU) and influence INT. Similar studies proved the relationship between MUI and ITU (Hong et al. 2011). Other studies showed (MUI) has a positive influence on the ease of use (EOU) of IS (Liu et al. 2010).

H5 Multimedia (MUI) has a significant direct relationship with intention to use (ITU).

H6 Multimedia (MUI) has a significant direct relationship with ease of use (EOU).

\subsection{Ease of use}

Ease of use (EOU) as defined by Davis "the degree to which a person believes that using a particular system would be free of effort" (Davis 1989, p. 320). It investigates the usability of the system and how much the user feel comfortable, especially the obligation to wear a device during the tour. It further considers the user's ability to reach the function that triggers what the user expects to reach. According to Davis $(1985,1989)$, EOU is one of the essential factors to predict user acceptance by measuring the effect of behaviour usage. EOU has a positive and 
significant influence in the intention to use (ITU) construct in related contexts (Chung et al. 2015; Haugstvedt and Krogstie 2012; Lee et al. 2015).

H7 Ease of use (EOU) has a significant direct relationship with intention to use (ITU).

\subsection{Role of guide}

Role of guide (ROG) is a construct created by this research and introduced as a new form of MR guidance in museums. It applies the essential guidance roles, such as exploring new venues, disseminating information and pathfinder. The aim of the quantitative study is to investigate whether the role of the guide is achieved through MuseumEye and whether its influence on the behaviour of future INT.

This aspect measures whether MuseumEye can perform the role of the human guide and compensate for the absence of a human tour guide. It also measures the effectiveness of disseminating the information required and help the visitor to explore and discover the exhibited items.

H8 Role of guide (ROG) has a significant direct relationship with intention to use (ITU).

The hypothesis investigates the perceived usefulness (USF) of using MuseumEye on the satisfaction of the guidance service and the effect on the intention to use (ITU). This study examines whether the role of guide (ROG) as a mediator influences the usefulness (USF) and the intention to use (ITU) as it is previously hypothesised.

H9 Role of guide (ROG) significantly mediates the relationship between usefulness (USF) and intention to use (ITU).

This hypothesis investigates whether the interactivity (INT) the user performs can enhance the satisfaction of being guided (ROG) by MuseumEye system and then it can positively motivate visitors to continue using it (ITU) in the future. As in $\mathrm{H} 4$, it was hypothesised the influence of interactivity (INT) on the intention to use (ITU).

H10 Role of guide (ROG) significantly mediates the relationship between interactivity (INT) and intention to use (ITU).

As previously hypothesised in $\mathrm{H} 5$, multimedia and UI (MUI) has an influence on the intention to use (ITU), this hypothesis investigates whether the good multimedia and UI can boost the satisfaction of being guided and achieved the desired role of guide (ROG) then correspondingly can influence the intention to use (ITU).
H11 Role of guide (ROG) significantly mediates the relationship between multimedia and UI (MUI) and the intention to use (ITU).

This hypothesis investigates whether the ease of using the system (EOU) can motivate the user to be guided (ROG) by MuseumEye then it can motivate the user to continue using the system in the future (ITU). This assumption was built based on the hypothesis of $\mathrm{H} 7$, which considers the ease of use (EOU) influences the intention to use (ITU).

H12 Role of guide (ROG) significantly mediates the relationship between ease of use (EOU) and intention to use (ITU).

\section{Empirical methodology}

\subsection{Data collection}

A mixed method data gather approach was implemented in this study using quantitative questions combined with Likert scales permitted the cross-analysis of open-ended inquiries with numerical ratings.

The first stage of the evaluation covers the practical implementation. The experiment started by giving participants a short tutorial on how to perform air tapping and make the rest of hand gestures. Then, the subjects were asked to start their tour by the autoloaded storytelling scenes and have the option to choose the interactive points that trigger the antique navigation scenes as depicted in Fig. 8. The second stage evaluates the MuseumEye application and the aspects depicted in the framework. In this stage, 200 questionnaires were distributed to the museum visitors who participated in the experiment. There are two types of museum visitors who participated in this experiment. The first who accepted the invitation of the experiment through a promotional video of the MuseumEye system was published on social media. The second who volunteered to participate when they saw other visitors experience new manners of touring.

The evaluation process expected different abilities to become accustomed to it, even after a discrete tutorial period. It is vital to embrace the user experience of the system, as it reflects the user's level of interest and engagement with the immersive experience. It also obstructs the flow of information that can be gained during the tour. Due to it being a new technology, it was expected that most of the users have not used the device before and that they would be unfamiliar with the hand interactions. The MR tour was supervised from the beginning to end to provide additional support and aid in technical difficulties. Each participant took between 30 and 40 min to finish the MR tour in the museum room of Tutankhamun. 


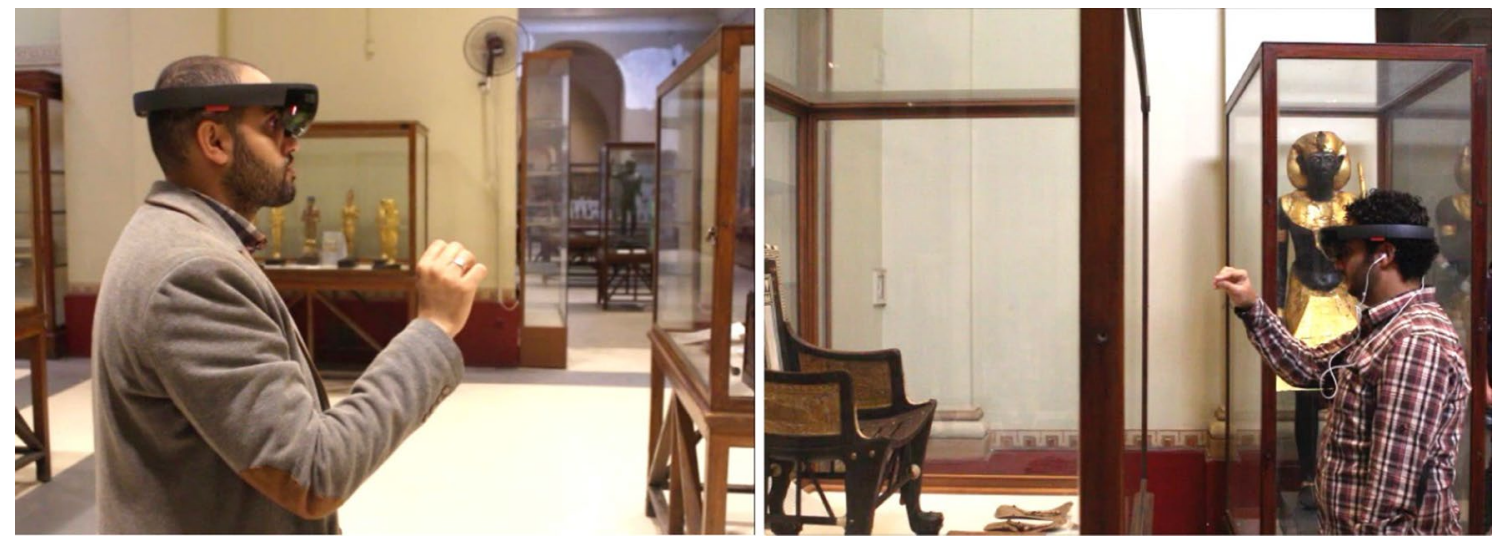

Fig. 8 Photo shots from experiencing MuseumEye at the Egyptian Museum in Cairo

The sample size of this study is based on previous museum studies by Bellotti et al. (2002), Lanir et al. (2013) and Liarokapis et al. (2008) intended to reach 200 participants as an adequate sample size. However, after discarding incomplete questionnaires, there were 171 valid participants. As a consequence, the final sample size was equal to a study conducted by Rubino et al. (2013). This sample size fits the analysis methods of exploratory factor analysis (EFA) and confirmatory data analysis (CFA). The sample size for the quantitative method was 122 participants.

For demographical analysis, the age of test subjects in relation to MR technology was a significant factor. In consideration, Dean (2002) pursued measuring the exposure of Information and Communication Technologies (ICTs) to children compared with adults. The study concluded that younger audiences expect the computer system to be part of museum installations and prefer interactivity in education systems (Best 2012). Hence, younger subjects may have different perspectives, levels of usability and skills than adults. Another assumption might take into consideration older audiences, often called 'silver surfers', who use computer software as a hobby and might be willing to use the museum systems (Owen et al. 2005). Accordingly, test subjects were categorised into the following age groups: 18 to $25,26-40$ and $41-60$.

Gender statistical analysis was conducted, with a view to exploring links between the use and adoption of MR technology across different genders. According to Owen et al. (2005), it is commonly known that males adopt technologies faster than females. Thus, the evaluation of gender aims to explore if this phenomenon occurs in the present study.

\subsection{Measures}

The questionnaire includes 35 questions with corresponding 5-point Likert scales to ratel one $=$ strongly disagree, to $5=$ strongly agree as employed in Hughes et al. (2005). The questionnaire took, on average, $8-10 \mathrm{~min}$ to be complete. The questionnaires employ (QUIS) questionnaire for user interface satisfaction which asses the user satisfaction of the system according to the interface and the usability aspects (Chin et al. 1988). The qualitative inquiries are an open space for visitors to write positive and negative testimonies concerning their experience of MuseumEye. Finally, as the study was deployed in the Cario Museum, questionnaire inquiries were translated into the Arabic language for ease of understanding.

The quantitative data were analysed using AMOS to compute the EFA and CFA, and the qualitative data were analysed thematically using Nvivo after translating the language from Arabic to English then transcript it intros the software. The questionnaires were piloted through academic students and staff to ensure the clarity and understandability of the questions was acceptable. Their feedback was taken into consideration, particularly in the submission of the ethical approval form by the ministry of antiquities in Egypt and the museum management staff.

\section{Results}

\subsection{Demographic results}

The sample size-171 participants-has fairly equal representation in terms of gender: $57.3 \%$ male and $42.7 \%$ female. Also, the participants were divided into three age groups, the age groups from 18 to 25 and 24-40 were represented the sample with percentages $47.4 \%$ and $42.1 \%$, respectively. These results represent a high level of interest for experiencing new technologies in museums from the younger groups in contrast with the older participants since the latter group resulted in $10.5 \%$ of the sample size.

In terms of the awareness of immersive technology, the participants were asked questions about their prior 
knowledge of AR, VR or MR technologies and whether they had experienced AR before. Indeed, 120 of participants (70.2\%) were aware of AR, VR or technology. Moreover, 73 participants $(42.7 \%)$ had heard of AR apps, such as Layar, Wikitude or Pokémon Go. 56 participants (32.7\%) had experience with wearing AR/VR/MR headsets/smart glasses. This was followed by an open question asking the participant to confirm what device they had worn before. Interestingly, these participants had experience with Oculus Rift, HTC Vive, Samsung VR Gear, Google Cardboard, VR Box or Microsoft HoloLens. Then, 44 (25.7\%) participants had experienced AR applications before, and $9(5.3 \%)$ had experienced AR in museums. All of the 9 participants had experienced AR in "The Wall of Knowledge" (Cultnat 2016) exhibition at the same museum.

\subsection{Descriptive analysis}

There were 27 system evaluation questions, which were formed and distributed to be adequate and sufficient for each construct, which in turn ranged between 3 and 5 questions per construct. Table 2 depicts the composition of the descriptive analysis including the minimum, maximum, standard deviation and the overall mean values of the seven aspects. The lowest minimum value of the aspects was the 'Interactivity' as 1.00, and the highest is 3.00 for two aspects, 'Usefulness' and 'Ease of Use'. Interestingly, all maximum values are 5.00. Regarding the mean values, the highest mean value is 4.55 for the "Intention to use" aspect, and the lowest mean value is 4.13 for the 'Interactivity'. Moreover, two mean values are identical as they are 4.33. Also, another two values are almost identical as they are 4.38 and 4.39 for the aspects' ease of use' and 'Role of being a guide', respectively. Generally, most of the mean values represent strong positive responses towards using the system in the targeted museum.

\subsection{Correlation and regression analysis}

Despite the fact that the majority of the survey questions extracted from previous studies, two round of factor analysis conducted in this study. It starts with exploratory factor analysis (EFA) in order to explore the structure of the relationship between the other variables and the emerged variable (Costello and Osborne 2005). As 'Role of a guide' is developed from the literature, and it is needed to be explored within the other variables. EFA followed by the confirmatory factor analysis (CFA). The need of testing CFA after EFA is simple because EFA explores those factors that best regenerate the variables under the maximum likelihood conditions, while CFA explores particular hypothesis concerning the nature of the factors (Gorsuch 1983). CFA was conducted by AMOS software in order to assess the unidimensionality. All the items were above .5, which is the acceptable cut off point (Comrey and Lee 2013). Table 3 presents the questions of the survey with EFA, CFA, AVE and Cronbach's Alpha.

Cronbach's Alpha $(\alpha)$ was used to measure the reliability of the survey, whereas the average variance extracted (AVE) used to test the convergent validity. Table 4 showed the correlation and discriminate validity, where the analysis indicated that the factors could test what the other variables cannot (Hair et al. 2010). The correlation, on the other hand, with diagonal value considers $<.01$, all of these indicators were statistically acceptable (Wooldridge 2015).

\subsection{Testing hypothesis}

The PROCESS is an analysis tool developed by Hayes (2013). PROCESS enables the test of the direct and indirect impact as well as it allows the test more than one mediators without sample size restrictions which are a key issue in other tools such as 'Structure Equation Modelling' (Hayes 2012, 2013). PROCESS results do not much differ from the structure equation model results; however, PROCESS calculate each equation sedately instead of concurrently (Hayes et al. 2017). The path considered significant when its confidence interval (CI) does not contain zero (Hayes 2013).

The mediation test runs through bootstrap (5000), which is the recommended number for bootstrap (Preacher and Hayes 2008). The bootstrap has been chosen to test the mediation impact as it deals with type I error (reject the true
Table 2 Descriptive analysis of all evaluation constructs for participants

\begin{tabular}{llllll}
\hline $\begin{array}{l}\text { Constructs in technology accept- } \\
\text { ance model }\end{array}$ & $\begin{array}{l}\text { No. of ques- } \\
\text { tions }\end{array}$ & Minimum & Maximum & Mean & Std. deviation \\
\hline Enjoyment (ENJ) & 5 & 2.20 & 5.00 & 4.37 & .52 \\
Usefulness (USF) & 4 & 3.00 & 5.00 & 4.37 & .51 \\
Multimedia and UI (MUI) & 4 & 1.00 & 5.00 & 4.33 & .62 \\
Ease of use (EOU) & 4 & 3.00 & 5.00 & 4.39 & .50 \\
Interactivity (INT) & 3 & 1.00 & 5.00 & 4.13 & .74 \\
Role of being a guide (ROG) & 4 & 2.00 & 5.00 & 4.38 & .61 \\
Intention to use (ITU) & 3 & 2.50 & 5.00 & 4.55 & .57 \\
\hline
\end{tabular}


Table 3 Construct reliability and convergent validity coefficient
Table 4 Correlation and discriminant validity

\begin{tabular}{|c|c|c|c|c|}
\hline & EFA & CFA & AVE & $\alpha$ \\
\hline Enjoyment & & & .50 & .83 \\
\hline The storytelling of King Tutankhamun is interesting & .77 & .77 & & \\
\hline Revealing the secret information around antiques is interesting & .71 & .65 & & \\
\hline I enjoyed exploring the exhibits with the help of MuseumEye & .69 & .71 & & \\
\hline I found this application enjoying in museum tours & 69 & .70 & & \\
\hline The content is engaging enough to focus on it till the end & 65 & .69 & & \\
\hline Usefulness & & & .51 & .80 \\
\hline The language is clear and understandable & 67 & .72 & & \\
\hline Images signposted during the narration are beneficial & .75 & .74 & & \\
\hline The information about the collection is satisfactory as expected & .66 & 65 & & \\
\hline I could clearly see the benefit of exploring virtual antiques & 69 & .73 & & \\
\hline Multimedia and UI & & & .57 & .83 \\
\hline I like the 3D characters (king, queen, maids...etc.) & .77 & .78 & & \\
\hline The historical music is engaging and supports the immersion & .75 & .72 & & \\
\hline The 3D scanned antiques are representing the authentic pieces & .71 & .72 & & \\
\hline I like the user interface design (buttons, graphics, icons... etc.) & .80 & .78 & & \\
\hline Ease of use & & & .50 & .81 \\
\hline It was comfortable to use the 'MuseumEye' application & .74 & .76 & & \\
\hline I did not experience nausea or headache using MuseumEye & 65 & 60 & & \\
\hline I could look around the room comfortably & 68 & .66 & & \\
\hline I could do air tap on the virtual objects appropriately & .73 & .78 & & \\
\hline Interactivity & & & 62 & .85 \\
\hline I could interact with the user interface as I expected & .80 & .75 & & \\
\hline I could move between scenes easily & .81 & .85 & & \\
\hline I could reveal all hints (information) from yellow circles easily & .74 & .77 & & \\
\hline Role of guide & & & 63 & .87 \\
\hline MuseumEye enhances the understanding of historical knowledge & .72 & .76 & & \\
\hline Visitors will be more independent in tours by using MuseumEye & .84 & .83 & & \\
\hline This application more like a tour guide than a tool for guidance & .79 & .82 & & \\
\hline I found MuseumEye is efficient in museums' navigation & .74 & .75 & & \\
\hline Intention to use & & & .50 & .84 \\
\hline I want to see more stories and more development in MuseumEye & 68 & .72 & & \\
\hline I prefer to use MuseumEye as a guiding tool in this museum & .75 & .73 & & \\
\hline To what extent you recommend MuseumEye for your friends to use? & 69 & 67 & & \\
\hline
\end{tabular}

\begin{tabular}{|c|c|c|c|c|c|c|c|c|}
\hline & ENJ & USF & MUI & INT & EOU & ROG & ITU & $\begin{array}{l}\text { Discri- } \\
\text { minant } \\
\text { validity }\end{array}$ \\
\hline ENJ & .71 & & & & & & & .71 \\
\hline USF & $.49 * *$ & .71 & & & & & & .71 \\
\hline MUI & $.47 * *$ & $.46^{* *}$ & .75 & & & & & .75 \\
\hline INT & $.45^{* *}$ & $.51 * *$ & $.48 * *$ & .71 & & & & .71 \\
\hline EOU & $.32 * *$ & $.29 * *$ & $.45^{* *}$ & $.36^{* *}$ & .79 & & & .79 \\
\hline ROG & $.46^{* * *}$ & $.43 * *$ & $.50 * *$ & $.53 * *$ & $.29 * *$ & .79 & & .79 \\
\hline ITU & $.35^{* *}$ & $.32 * *$ & $.42 * *$ & $.37 * *$ & $.29 * *$ & $.66^{* *}$ & .71 & .71 \\
\hline
\end{tabular}

**Correlation is significant at the .01 level (2-tailed)

Numbers in bold are results of the correlations for the same constructs which equals the Discriminant validity 
null hypotheses) and can provide correct results despite the sample size (Claudy et al. 2016; Preacher and Hayes 2008).

The hypotheses was tested using PROCESS with both direct and indirect relationships measured, as depicted in Table 5 (Hayes 2017). The indirect effect between the constructs (usefulness, interactivity, multimedia and UI, and Ease of use) with the intention of use represented in two models where each model contains one mediator, namely role of guide for model 1 and enjoyment for model 2. The results demonstrated that role of guide significantly mediated the relationship between usefulness and the intention to use ( $\beta=.19$, CI $95 \%=.08, .33 ; R^{2}=.27$ ), supported H9. Model 2 showed that enjoyment does not mediate the relationship between usefulness and intention to use $(\beta=.03$, CI $95 \%=.06, .12 ; R^{2}=.25$ ) rejected $\mathrm{H} 3$. Model 1 further represented the significant mediation of the role of guide between interactivity, multimedia, ease of use from one side and the intention of use form the other side $(\beta=.27$, CI $95 \%=.18$, $\left..40 ; R^{2}=.44\right),\left(\beta=.28, \mathrm{CI} 95 \%=.16, .48 ; R^{2}=.45\right),(\beta=.21$, CI $\left.95 \%=.09, .39 ; R^{2}=.45\right)$, respectively supporting H10, $\mathrm{H} 11$ and H12.

The direct impact indicated that only the multimedia variable has a significant impact on intention to use $(\beta=.35$, $t=4.5, p<.01)$, supported H5. Usefulness $(\beta=.03, t=.34$, $p>.05)$, enjoyment $(\beta=.06, t=.75, p>.05)$, interactivity $(\beta=.02, t=.29, p>.05)$, and ease of use $(\beta=.10, t=1.07$, $p>.05)$, do not have a direct impact on intention to use. Rejected H1, H2, H4, and H7. Finally, the results showed a significant direct impact of the role of guide on the intention to use $(\beta=.61, t=9.5, p<.01)$, supported H8. As well as, there is a significant direct impact of multimedia and UI on ease of use ( $\beta=.44, t=8.56, p<.01)$, supporting H6.
Figure 9 depicts the research framework with regression coefficient values between the constructs.

\subsection{Responses to open-ended questions}

The participants were enthusiastic and positive in their responses to the open-ended questions, and 122 out of 171 participants responded in their questionnaires. The tables below analyse the qualitative responses quantitatively by frequency. Table 6 shows the aspects that the participants considered the most significant factors of the design and application of MuseumEye. Table 7 depicts the open questions that investigate the aspects which were not preferable and needed to be improved. Note that frequencies in Tables 6 and 7 refer to concepts rather than exact phrases.

Based on the total results of the tables, contribution to the best aspects was higher than questions relating to improvements, given it was 102 responses against 31 . The aspect the participants most had views on was 'Multimedia and UI', with 20 comments, followed by the 'Interaction' aspect with 18 comments. 'Usefulness' was mentioned 17 times, and 'Enjoyment' aspect mentioned 15 times. Then, 'Ease of use' was mentioned 14 times, and finally, 'Role of being a Guide' was mentioned six times.

Regarding Table 6, which investigated potential improvements and limitations of the MuseumEye application, six participants commented on how King Tutankhamun looked authentic compared with statues. Another group that comprised of 5 participants complained about the narrow field of view. Additionally, a further group of five participants complained about difficulties with the interactions and the lack of instructions. Finally, the open question provided crucial

Table 5 Hypotheses tests

\begin{tabular}{|c|c|c|c|c|c|c|c|}
\hline \multicolumn{4}{|c|}{ Indirect Effect } & \multicolumn{4}{|c|}{ Direct Effect } \\
\hline & & $\begin{array}{l}\text { Model } 1 \\
\rightarrow \mathrm{ROG} \rightarrow \mathrm{ITU} \\
\end{array}$ & $\begin{aligned} & \text { Model } 2 \\
& \rightarrow \mathrm{ENJ} \rightarrow \mathrm{ITU} \\
&\end{aligned}$ & & & $\beta$ & $\mathrm{t}$ \\
\hline \multirow[t]{2}{*}{ USF } & $\beta$ & $.19^{* *}$ & .03 & \multirow{2}{*}{ H1 } & \multirow{2}{*}{$\mathrm{USF} \rightarrow \mathrm{ITU}$} & \multirow{2}{*}{.03} & \multirow{2}{*}{.34} \\
\hline & $\mathrm{R}^{2}$ & .27 & .25 & & & & \\
\hline \multirow{4}{*}{ INT } & MSE & .28 & .21 & \multirow{2}{*}{$\mathrm{H} 2$} & \multirow{2}{*}{$\mathrm{ENJ} \rightarrow \mathrm{ITU}$} & \multirow{2}{*}{.06} & \multirow{2}{*}{.75} \\
\hline & $\beta$ & $.27^{* *}$ & & & & & \\
\hline & $\mathrm{R}^{2}$ & .44 & & \multirow{2}{*}{$\mathrm{H} 4$} & \multirow{2}{*}{ INT $\rightarrow$ ITU } & \multirow{2}{*}{.02} & \multirow{2}{*}{.29} \\
\hline & MSE & .19 & & & & & \\
\hline \multirow[t]{3}{*}{ MUI } & $\beta$ & $.28^{* *}$ & & \multirow{2}{*}{ H8 } & \multirow{2}{*}{$\mathrm{ROG} \rightarrow \mathrm{ITU}$} & \multirow{2}{*}{$.61^{*}$} & \multirow{2}{*}{9.5} \\
\hline & $\mathrm{R}^{2}$ & .45 & & & & & \\
\hline & MSE & .19 & & \multirow{2}{*}{ H5 } & \multirow{2}{*}{$\mathrm{MUI} \rightarrow \mathrm{ITU}$} & \multirow{2}{*}{$.35^{*}$} & \multirow{2}{*}{4.5} \\
\hline \multirow[t]{3}{*}{ EOU } & $\beta$ & $.21^{* *}$ & & & & & \\
\hline & $\mathrm{R}^{2}$ & .45 & & H7 & $\mathrm{EOU} \rightarrow \mathrm{ITU}$ & .10 & 1.07 \\
\hline & MSE & .18 & & $\mathrm{H} 6$ & $\mathrm{MUI} \rightarrow \mathrm{EOU}$ & $.44^{*}$ & 8.56 \\
\hline
\end{tabular}




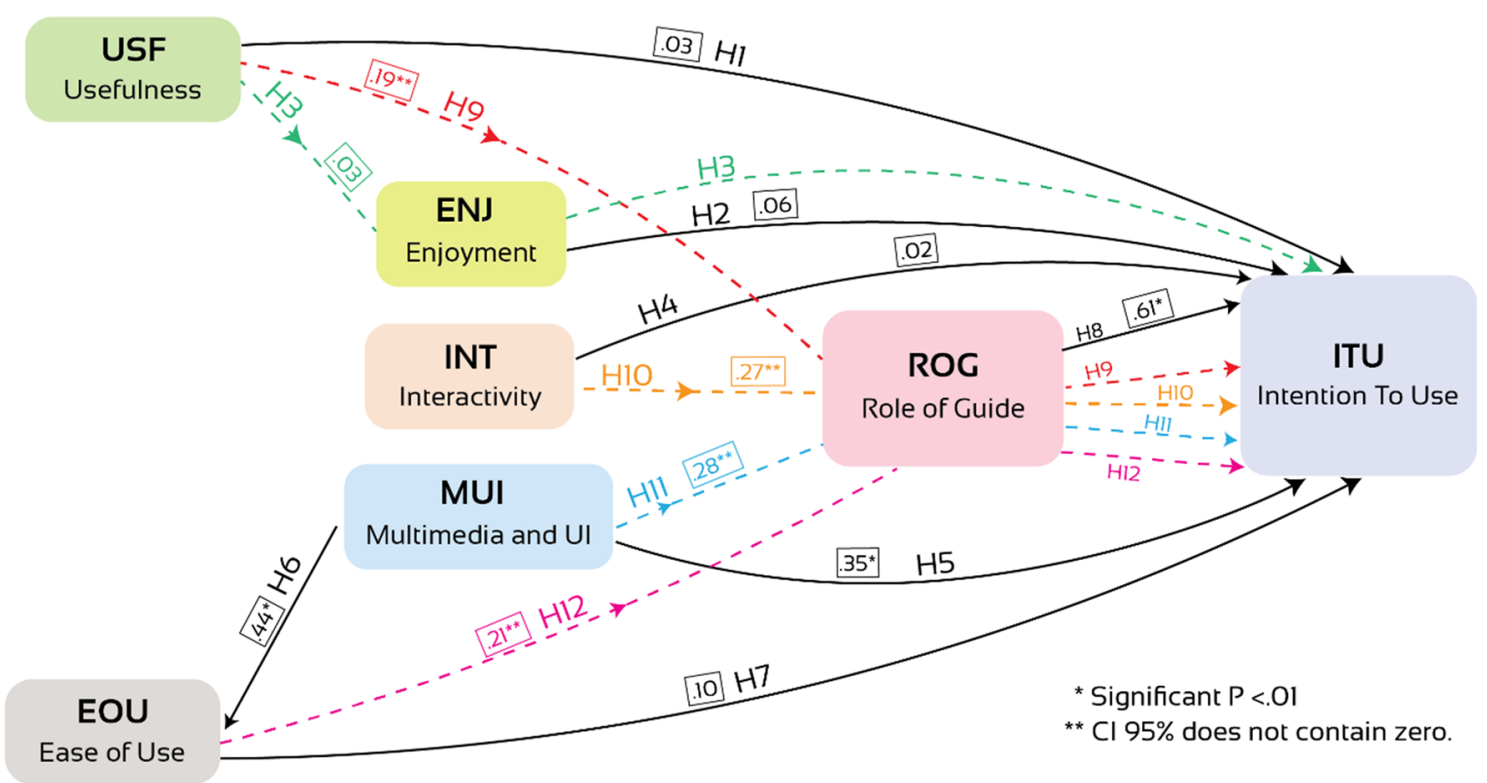

Fig. 9 Conceptual framework

Table 6 Participants' responses on open questions that explore the best aspects

What are the best aspects of MuseumEye?

Enjoyment: "The application was interesting, entertaining and engaging"

Immersion: "Isolation from surrounding people and the museum room and entering a pharaonic environment and the music helped 16 me to make the experiment more immersive"

Multimedia and UI: "I like the graphics, images, music and the presentation manner"

Role of being a guide: "It can take the role of the museum guide or the labels' role, and it gives me information on the issue I want 6 to know about"

Scenario and storytelling: "I want to see more storytelling and other contexts developed into MuseumEye" 8

Usefulness: "It contains beneficial information and very simple explanations" 17

Ease of use: "The system and very easy. It was very simple, and I managed to navigate the system" 14

Interaction: "The navigation of the statues makes me feel that I was engaged more" 18

Content is not distracting: "The presentation of the king did not distract me out of the content of the museum" 4

Independence: "The visitor gets privacy", "More independence" 7

Overall satisfaction phrases: "I like the idea and its implementation" 12

The willingness of future use: "I wish to see it permanently in the museum" 4

Total 102

Table 7 Participants' responses to the aspects that need to be improved

\begin{tabular}{lc}
\hline What are other aspects, which are not so good about MuseumEye? & Frequency \\
\hline FOV: "Field of view was very narrow" & 5 \\
Other language support: "I wish to see the Arabic version" & 3 \\
HoloLens weight: "Little bit heavy" & 3 \\
More stories and more content: "I wish I can see a menu that can list all the museum collec- & 4 \\
tions which have 100 antiques" & 5 \\
Usability: "Swiping and clicking is somehow cumbersome and need more instructions" & 5 \\
Graphics and 3D models: "The statue of Tutankhamun was not identical to the authentic one" & 6 \\
Need more time to use: "The period of using it was so short" & 3 \\
Total & 31
\end{tabular}


information used to evaluate the efficiency of the MuseumEye as an information system.

\section{Discussion}

According to the results of the participants' profiles, the differences in the age groups showed different levels of AR/VR awareness. According to Dean (2002), exposure to information systems in younger age groups is greater than adults. This was apparent in the results, which showed a higher awareness of the age group 18-. The older age group 26-40 had a greater awareness than the 41-60 age group. These findings indicate that the level of computer skills and the willingness of using IT is greater in younger individuals. However, $10 \%$ of the sample was above the age of 40 and showed an adequate level of awareness and experience of AR/VR.

As stated in the results, male participants showed a higher level of awareness and experience of AR/VR than the female participants, which coincides with what Owen et al. (2005) study. Generally, the sampled participants showed a sufficient level of familiarity with the technology, which encouraged participants to embrace MR technology during the experiment. The quantitative results indicated that the role of the MR guide mediated the relations between guests and extended the intention to use. Moreover, not all the relations between the constructs and the intention to use were strong. Figure 10 represents the structured model after the weak correlations between constructs were removed.
The perceived usefulness of MuseumEye does not influence on the intention to use and does not collate with previous studies (Chung et al. 2015; Haugstvedt and Krogstie 2012; Lee et al. 2015). However, the perceived usefulness influenced the intention to use when the guide role mediate the relationship $\left(\beta=.19, R^{2}=.27\right.$, CI $95 \%=.08, .33$ ). However, it did not encourage the intention to use when the perceived enjoyment mediates the relationship.

This result highlights the significance of the guide role of MuseumEye. This outcome corresponds with the outcomes of similar studies that used mobile guide such as Haugstvedt and Krogstie (2012) resulted $\left(R^{2}=.38, p<.001\right)$, Lee et al. (2015) resulted $(\beta=.23, p<.05)$ and Balog and Pribeanu (2010) resulted $(\beta=.24, t$ value $=2.27, p<.05)$. Thus, the MusuemEye provided a virtual guide proximal to a human guide who accompanies a visitor wherever he/she goes. Moreover, disseminating the information like a human guide boosts the usefulness of the application, which impacts on the visitors' intention of future usage (Joachims et al. 1997). Due to the uniqueness of this study, it was not easy to find a similar study that measured indirect relationships that can embed mediators between the measured constructs. Moreover, mediating the role of guide in the framework is what this study contributes to evaluate the MR guide systems. Regarding the qualitative results on the perceived usefulness, 17 participants stated that there was "beneficial information and very easy explanations" in the open-ended questions.

This study did not show a significant influence on the intention to use MuseumEye in the future. This result contradicts the results of other studies (Haugstvedt and Krogstie 2012; Lee et al. 2015) and the reason is the perceived

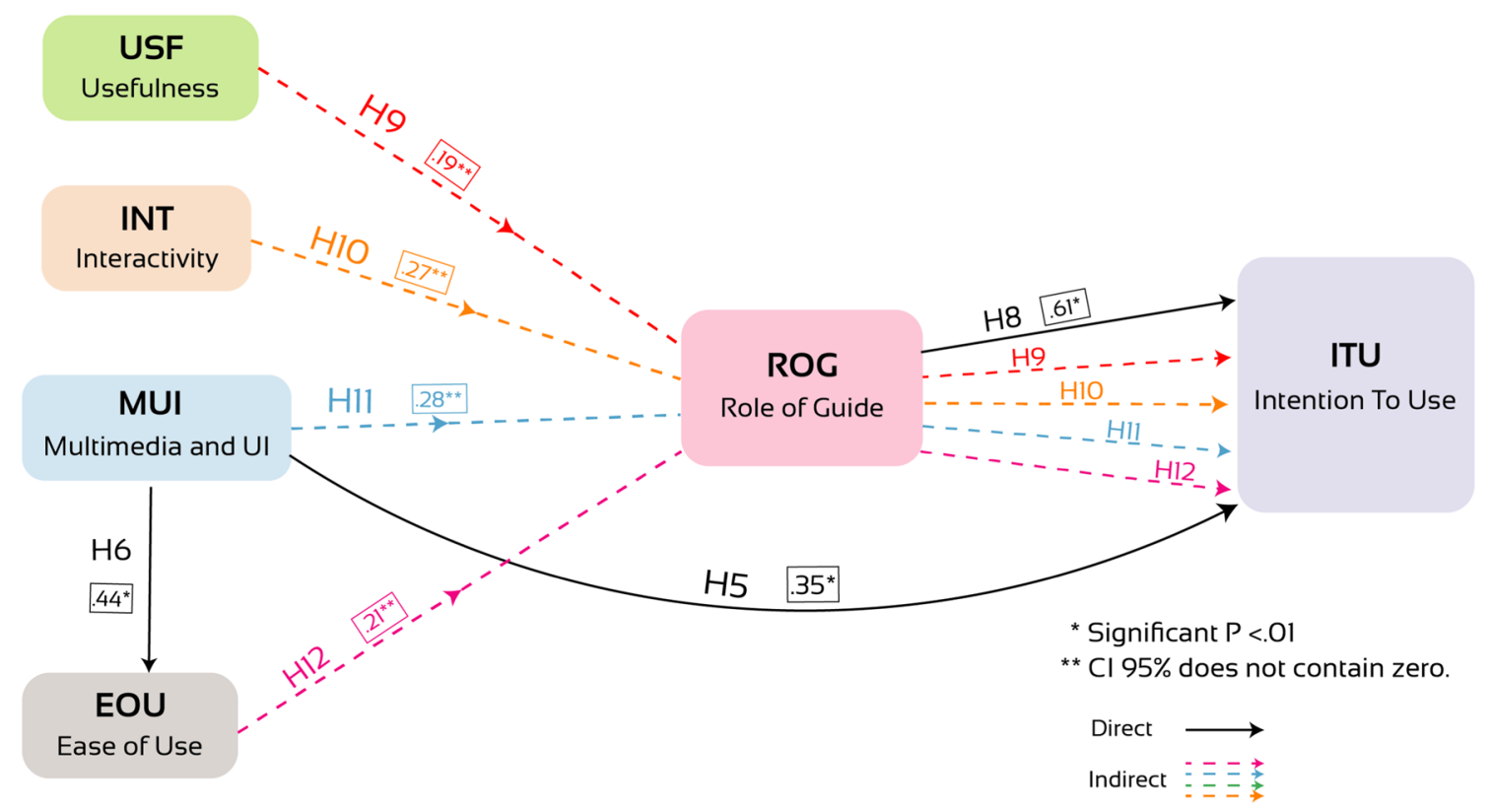

Fig. 10 The structured model 
enjoyment might not be sufficient enough to be an intrinsic motivation for the usage. The qualitative analysis showed 15 participants who stated: "the application was interesting, entertaining and engaging". This theme indicates that this construct was achieved successfully in the MR guide, and it can satisfy part of the personal context defined by Falk and Dierking (2016).

The perceived interaction with MuseumEye showed less correlation with the intention to use the system in the future; however, it collates significantly when the role of guide mediates the two constructs, as indicated in the results ( $\beta=.27$, CI 95\% =.18, .40; $\left.R^{2}=.44\right)$ of Liu et al. (2010) who measured the student's interactions with the online learning websites and its correlation with the intention to use, and it resulted $(\beta=.12, p<.5)$. The qualitative results for this construct were positive, as 18 participants commented that "the navigation of the statues makes me feel that I was engaged more". This can satisfy part of the social-cultural context that construct the museum experience according to Falk and Dierking (2016), as visitors can interact with other visitors either who are immersed in the MR experience or not.

The multimedia and UI did not have a positive influence on the intention to use MuseumEye directly but did when the role of guide abilities mediate the relationship. The study showed higher correlations to the intention to use MuseumEye more than other studies, as it resulted $\left(\beta=.28, R^{2}=.45\right.$, CI $95 \%=.16, .48)$. For instance, a study such as Hong et al. (2011) who examined the interface design of the online learning websites on the intention to use it and it resulted $(\beta=.10, p<.05)$. This can indicate that when users engage with multimedia content and the UI, that affect positively on future usage.

Also, multimedia and UI had a strong influence on the perceived ease of use $(\beta=.44, t=8.56, p<.01)$. This correlates with other studies such as Liu et al. (2010), $(\beta=.47$, $p<.001)$ and Cho et al. (2009), $(\beta=.55, p<.001)$. In addition, good multimedia and UI design reduce the fear of using computers or systems and motivate users to use it (Shneiderman and Plaisant 2010). The qualitative analysis showed that participants enjoyed interacting with hand gestures and the images, videos, visual effects and the 3D sounds. About 20 participants stated: "I like the graphics, images, music and the presentation manner". The designed multimedia and Microsoft HoloLens itself helped the visitors to feel the immersion of the virtual environment, as mentioned previously.

The perceived ease of using MuseumEye did not influence the intention to use; however, it did when the guide roles mediate the two constructs. This means the ease of using the system alongside the guide abilities can encourage the user to use the system in the future. Per the results of this study $\left(\beta=.21\right.$, CI $\left.95 \%=.09, .39 ; R^{2}=.45\right)$ which correlate with Haugstvedt and Krogstie (2012) which measured the influence of the perceived ease of using the AR mobile guide on the willingness to use it $(\beta=.15, t=2.060, p<.05)$.

Moreover, Liu et al. (2010) explored the ease of using the online learning systems on the intention to use $(\beta=.12$, $p<.05)$. Also, Luarn and Lin (2005) who measured the perceived ease of use on mobile banking on the willingness to use it $(\beta=.33, t=6.61, p<.01)$. The rationale is the tutorial of using MuseumEye prior to the participants' tour enhanced perceiving the usability and the ease of use. However, that was not enough for motivating users to use the system in the future till the users were able to instruct the virtual guide to give information in a particular time and location (Jan et al. 2009). The open questions revealed that 16 visitors commented on how they were immersed in a pharaonic environment in this ancient time with the king and his guards. However, five visitors complained about Microsoft HoloLens' narrow field of view and claimed that it blocked their sight and made visuals fall in a narrow rectangle.

The role of the guide is the most vital aspect of this study, as this research introduces a replacement guide for existing human-guided tours using the 'MuseumEye' application.

Interestingly, the guidance capabilities of the MuseumEye system had the most substantial influence on the intention to use the system in museums ( $\beta=.61, t=9.5, p<.01)$. This result proves the significance of the role of guide on the intention to use among all other measured constructs. These statistics conclude that the MuseumEye system solves the current human guiding problem which exists in the targeted museum. The qualitative results showed that the participants enjoyed the way the system can help the user gather information, along with its ability to engage younger visitors in overcoming the complexity of delivering a great deal of historical information in this context. Despite these positive comments, there were some other arguments and critical comments that touched on the social interactions during the tour and the social isolation that could occur.

However, the system can enable shared experiences between two or more users of the system, and in this case, social interaction might be encouraged. After demonstrating the role of guide in MuseumEye as proof of MR guide concept, the following table-Table 8-conducts a comparison between MuseumEye and the human guides according to the roles of guides defined by various scholars (Almagor 1985; Cohen 1985; Holloway 1981) and recent studies (Goodwin 2007; Zhang and Chow 2004). Indeed, it is impossible to compare human cognitive skills with AI or technological functions. However, this comparison is a way to push MR guides to rise as a potential substitute and a successful guided method in museums. 


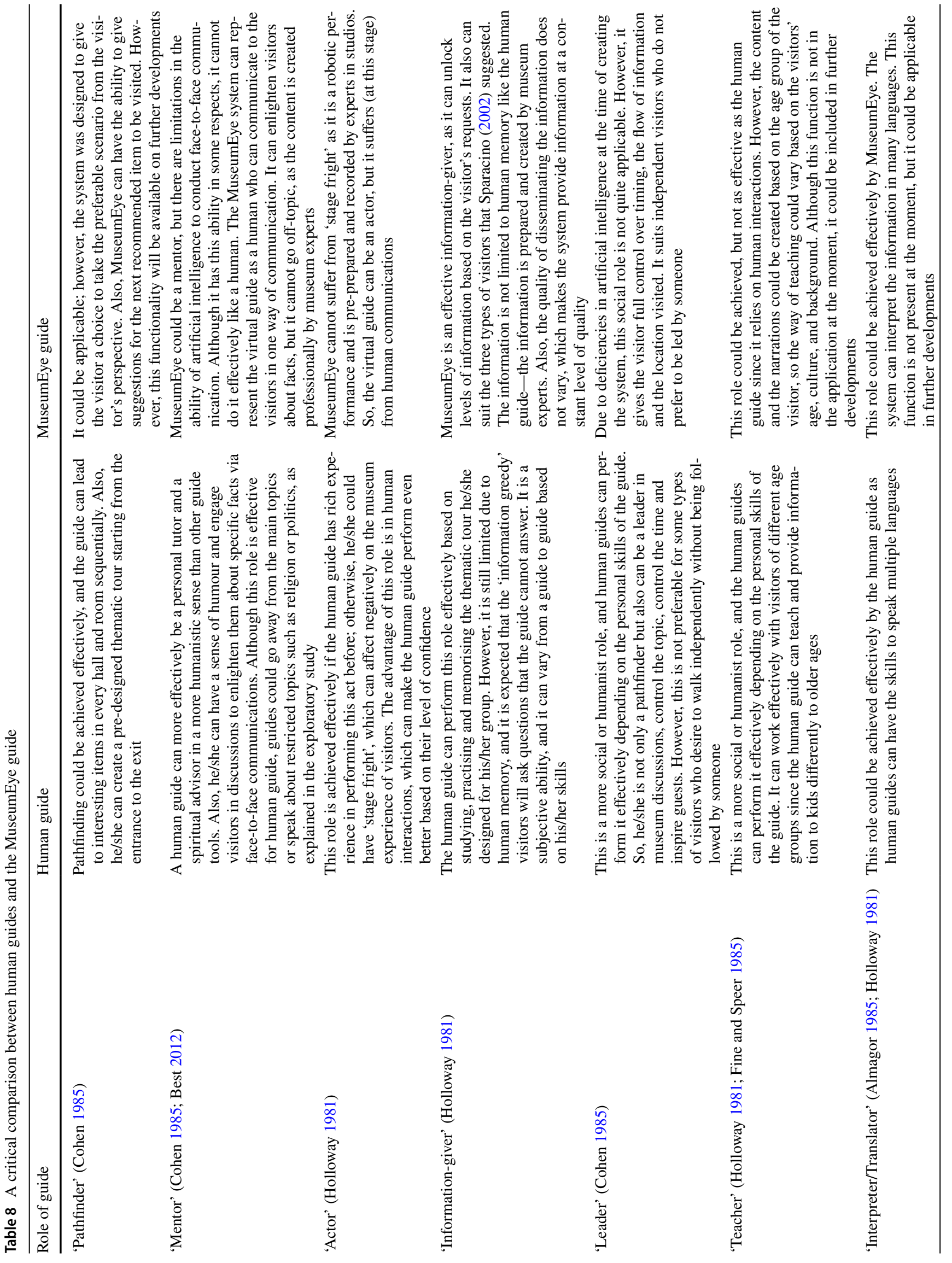




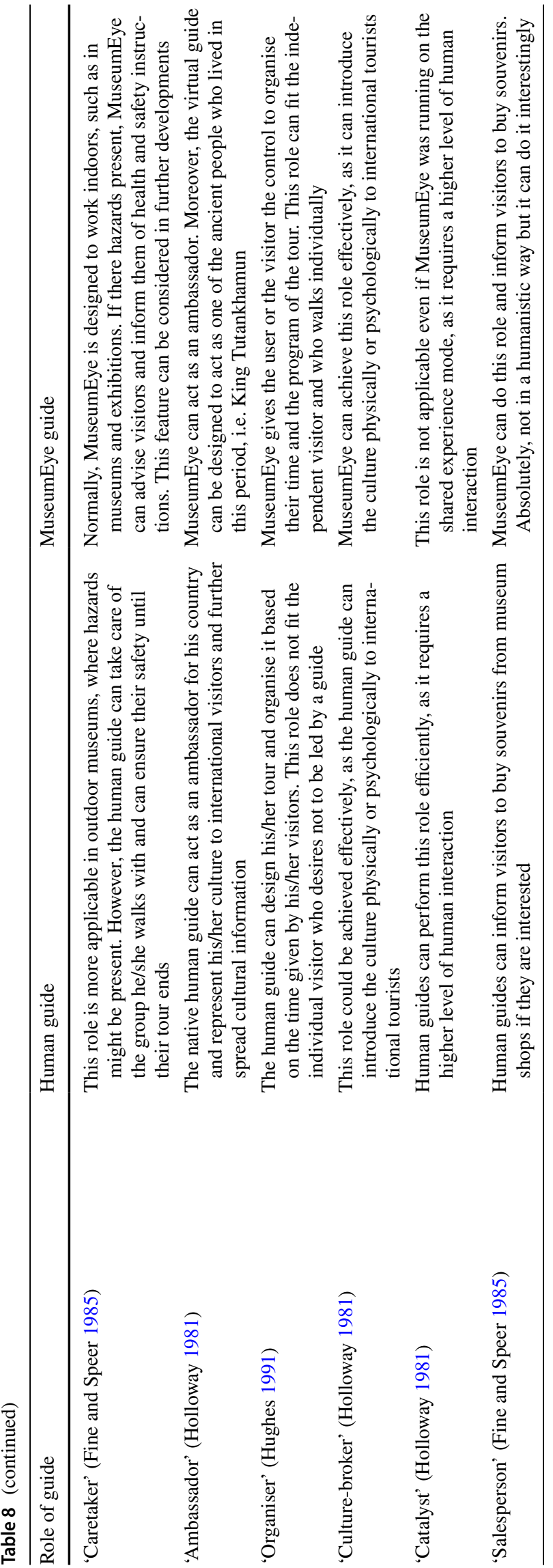

\section{Conclusion}

To conclude, this research introduced a framework for assessing a novel spatial MR guide for enhancing the traditional museum experience by replacing the human tour guide with a virtual model. The primary contribution of this paper is the critical examination of the role of the guide in MR technologies for museums. This study proved that designing the guide system according to the main roles of guides that are stated in the most cited museum studies can stimulate the visitors' intention to use the system in the future. The framework introduced in this study is the first conceptual framework that can measure the role of the tour guide in MR systems among relevant significant factors, and the willingness of future use by museum users is to be expected.

The limitations of this study, firstly, due to the museum's restriction on conducting experiments with foreign visitors, the participants of our study are Egyptian visitors only. This aspect limited the diversity of participants in terms of their backgrounds and cultural perspectives. Secondly, it is vital to make participants embrace the user experience of the system before the experiment, as it reflects the user's level of interest and engagement with the immersive experience. It also obstructs the flow of information that can be gained during the tour.

Future research Further research can put more focus on utilising the new editions of holographic devices to mature the role of the guide with more capabilities. By the time of this research, the second version of Microsoft HoloLens was released, and the opportunity of incorporation of the artificial intelligence (AI) (Pollefeys 2017; Goode 2019) can have greater potential to maximise the museum virtual guides abilities.

The findings of this study have greater implications in other areas of tourism and open prospects of MR in the cultural heritage sector, and it takes the traditional museum experience to a new level of engagement and interactive experience. The MR technique, currently deployed in museums, could be an important vehicle for driving the tourism industry towards achieving success, and thus this might directly reflect on Egypt's economy. Through adopting the technology, the awareness of the wearable technology and the ability to interact with holograms will be familiar in the context of museums and cultural heritage. It is especially relevant when trying to reach the younger Egyptian generations, through using new technology that creates rich, fun and engaging experiences for visitors, rather than touring in a traditional method. This method enriches the historical knowledge of both native and non-native visitors.

Acknowledgements This study was constructed from a $\mathrm{PhD}$ thesis by the 1 st author. We would like to thank the Egyptian museum in 
Cairo curators for their help and support. Also, we want to thank The Egyptian government for facilitating the experiment and getting all approvals requested.

Author's contribution This paper is constructed from my $\mathrm{PhD}$ thesis under title "Virtual Guidance using Mixed Reality in Historical Places and Museums" in 2019. The co-authors contributed as follows. MM is the $\mathrm{PhD}$ supervisor who actively contributed text and critical analysis of the work presented in this article. ZA-K is an expert in statistical analysis and he contributed by reviewing the PROCESS statistical method to demonstrate the quantitative results in a better form. CS is a computer programmer and he helped in the technical programing issues in the Mixed Reality system; in addition, he enhanced the clarity of discussion section of the article.

Funding This project was funded by Newton-Mosharafa scholarship which was managed by the British council in Egypt.

\section{Compliance with ethical standards}

Conflict of interest The authors declare that there is no conflict of interest.

Consent for publication This manuscript has not been published and is not under consideration for publication elsewhere.

Ethics approval The project was granted an ethics approval from Staffordshire university through an ethics committee as part of my $\mathrm{PhD}$ project in 2018. The ethics approval included revealing human figures who participated voluntarily in the study and signed the consent forms.

\section{References}

Ajzen I, Fishbein M, Heilbroner RL (1980) Understanding attitudes and predicting social behavior, vol 278. Prentice-hall, Englewood Cliffs, NJ

Albrecht U-V, Folta-Schoofs K, Behrends M, Von Jan U (2013) Effects of mobile augmented reality learning compared to textbook learning on medical students: randomized controlled pilot study. J Med Internet Res 15(8):e182

Alizadehsalehi S, Hadavi A, Huang JC (2019) Virtual reality for design and construction education environment. In: AEI 2019: integrated building solutions-the national agenda. American Society of Civil Engineers Reston, pp 193-203

Alizadehsalehi S, Hadavi A, Huang JC (2020) From BIM to extended reality in AEC industry. Autom Constr 116:103254

Allison C (2018) Asus mixed reality headset review. Accessed from https://www.wareable.com/vr/asus-mixed-reality-headset-revie w-7465. Accessed 10 Jan 2018

Almagor U (1985) A tourist's "vision quest" in an African game reserve. Ann Tour Res 12(1):31-47

Antlej K, Horan B, Mortimer M, Leen R, Allaman M, Vickers-Rich P, Rich T (2018) Mixed reality for museum experiences: a cocreative tactile-immersive virtual coloring serious game. Paper presented at the 2018 3rd Digital heritage international Congress (DigitalHERITAGE) held jointly with 2018 24th International conference on virtual systems and multimedia (VSMM 2018)

Antón C, Camarero C, Garrido M-J (2018) Exploring the experience value of museum visitors as a co-creation process. Curr Issues Tour 21(12):1406-1425
Antoniou A, Dejonai MI, Lepouras G (2019) 'Museum Escape': a game to increase museum visibility. Paper presented at the International conference on games and learning alliance

Ardito C, Buono P, Desolda G, Matera M (2018) From smart objects to smart experiences: an end-user development approach. Int J Hum Comput Stud 114:51-68

Atkinson T (2018) Product review: Dell Visor Windows MR headset. Accessed from https://techtrends.tech/tech-trends/product-revie w/product-review-dell-visor-windows-mr-headset/. Accessed 04 Jan 2018

Avramova V, Yang F, Li C, Peters C, Skantze G (2017) A virtual poster presenter using mixed reality. Paper presented at the International conference on intelligent virtual agents

Ayeh JK, Au N, Law R (2013) Towards an understanding of online travellers' acceptance of consumer-generated media for travel planning: integrating technology acceptance and source credibility factors. In: Cantoni L, Xiang Z (eds) Information and communication technologies in tourism 2013. Springer, Berlin, pp 254-267

Balog A, Pribeanu C (2010) The role of perceived enjoyment in the students' acceptance of an augmented reality teaching platform: a structural equation modelling approach. Stud Inform Control 19(3):319-330

Bekele MK, Pierdicca R, Frontoni E, Malinverni ES, Gain J (2018) A survey of augmented, virtual, and mixed reality for cultural heritage. J Comput Cult Herit 11(2):1-36

Bellotti F, Berta C, De Gloria A, Margarone M (2002) User testing a hypermedia tour guide. IEEE Pervasive Comput 1(2):33-41

Best K (2012) Making museum tours better: understanding what a guided tour really is and what a tour guide really does. Mus Manag Curatorship 27(1):35-52

Boland P, Johnson C (1996) Archaeology as computer visualization: virtual tours of Dudley Castle c. 1550. Br Mus Occas Pap 114:227-233

Bray MZB (2018) What is mixed reality? Accessed from https://docs. microsoft.com/en-us/windows/mixed-reality/mixed-reality. Accessed 15 May 2018

Brůha L, Laštovička J, Palatý T, Štefanová E, Štych P (2020) Reconstruction of lost cultural heritage sites and landscapes: context of ancient objects in time and space. ISPRS Int J Geo-Inf 9(10):604

Burgard W, Cremers AB, Fox D, Hähnel D, Lakemeyer G, Schulz D, Thrun S (1999) Experiences with an interactive museum tourguide robot. Artif Intell 114(1):3-55

Cameron DF (1968) A viewpoint: The museum as a communications system and implications for museum education. Curator Mus J 11(1):33-40. https://doi.org/10.1111/j.2151-6952.1968.tb008 83.

Cantatore E, Lasorella M, Fatiguso F (2020) Virtual reality to support technical knowledge in cultural heritage. The case study of cryptoporticus in the archaeological site of Egnatia (Italy). Int Arch Photogramm Remote Sens Spatial Inf Sci 44:465-472

Carrozzino M, Bergamasco M (2010) Beyond virtual museums: experiencing immersive virtual reality in real museums. J Cult Herit 11(4):452-458

Chin JP, Diehl VA, Norman KL (1988) Development of an instrument measuring user satisfaction of the human-computer interface. Paper presented at the Proceedings of the SIGCHI conference on Human factors in computing systems

Cho V, Cheng TE, Lai WJ (2009) The role of perceived user-interface design in continued usage intention of self-paced e-learning tools. Comput Educ 53(2):216-227

Choi $\mathrm{H}$ (2014) The conjugation method of augmented reality in museum exhibition. Int J Smart Home 8(1):217-228

Chung N, Han H, Joun Y (2015) Tourists' intention to visit a destination: the role of augmented reality (AR) application for a heritage site. Comput Hum Behav 50:588-599 
Claudy MC, Peterson M, Pagell M (2016) The roles of sustainability orientation and market knowledge competence in new product development success. J Prod Innov Manag 33:72-85

Clini P, Quattrini R, Frontoni E, Pierdicca R, Nespeca R (2017) Real/ not real: pseudo-holography and augmented reality applications for cultural heritage. In: Handbook of research on emerging technologies for digital preservation and information modelling. IGI Global, Philadelphia, pp 201-227

Cohen E (1985) The tourist guide: the origins, structure and dynamics of a role. Ann Tour Res 12(1):5-29. https://doi. org/10.1016/0160-7383(85)90037-4

Comrey AL, Lee HB (2013) A first course in factor analysis. Psychology Press, New York

Cortana J (2017) The future of holograms in museums. Accessed from https://www.cortinaproductions.com/holograms-in-museums/. Accessed 15 Mar 2018

Costello AB, Osborne JW (2005) Best practices in exploratory factor analysis: four recommendations for getting the most from your analysis. Pract Assess Res Eval 10(7):1-9

Craig AB (2013) Augmented reality concepts. Morgan Kaufmann, Los Altos

Cultnat (2016) Participation in the Egyptian Museum's celebration of its 114th anniversary. Accessed from http://www.cultn at.org/NewsDetails/350/Participation_in_the_Egyptian_Museu m\%E2\%80\%99s_Celebration_of_its_114th_Anniversary. Accessed 15 Apr 2018

Damala A, Stojanovic N (2012) Tailoring the adaptive augmented reality (A2R) museum visit: identifying cultural heritage professionals' motivations and needs. Paper presented at the 2012 IEEE International symposium on mixed and augmented reality-arts, media, and humanities (ISMAR-AMH)

Damala A, Cubaud P, Bationo A, Houlier P, Marchal I (2008) Bridging the gap between the digital and the physical: design and evaluation of a mobile augmented reality guide for the museum visit. Paper presented at the Proceedings of the 3rd international conference on Digital Interactive Media in Entertainment and Arts, Athens, Greece

Davis FD (1985) A technology acceptance model for empirically testing new end-user information systems: theory and results. Massachusetts Institute of Technology, Cambridge

Davis FD (1989) Perceived usefulness, perceived ease of use, and user acceptance of information technology. MIS Quarterly 13(3):319340. https://doi.org/10.2307/249008

Davis FD, Bagozzi RP, Warshaw PR (1992) Extrinsic and intrinsic motivation to use computers in the workplace. J Appl Soc Psychol 22(14):1111-1132

Dean D (2002) Museum exhibition: theory and practice. Routledge, London

Doering ZD, Pekarik AJ (1996) Questioning the entrance narrative. J Mus Educ 21(3):20-23

Ducey AJ, Coovert MD (2016) Predicting tablet computer use: an extended technology acceptance model for physicians. Health Policy Technol 5(3):268-284

Duffy C (1989) Museum visitors - a suitable case for treatment. Paper presented at the unpublished paper for the Museum Education Association of Australia conference

Falk JH, Dierking LD (2016) The museum experience revisited. Routledge, London

Fenu C, Pittarello F (2018) Svevo tour: the design and the experimentation of an augmented reality application for engaging visitors of a literary museum. Int J Hum Comput Stud 114:20-35

Fevgas A, Fraggogiannis N, Tsompanopoulou P, Bozanis P (2014) The iMuse Virtual Museum: towards a cultural education platform. Paper presented at the IISA 2014, the 5th international conference on information, intelligence, systems and applications
Fine EC, Speer JH (1985) Tour guide performances as sight sacralization. Ann Tour Res 12(1):73-95

Fishbein M, Ajzen I (1975) Belief, attitude, and behavior: an introduction to theory and research. Addison Wessley, Reading

Flavián C, Ibáñez-Sánchez S, Orús C (2019) The impact of virtual, augmented and mixed reality technologies on the customer experience. J Bus Res 100:547-560

Goode L (2019) Microsoft's HoloLens 2 puts a full-fledged computer on your face. Accessed from https://www.wired.com/story/micro soft-hololens-2-headset/. Accessed 28 Feb 2019

Goodwin C (2007) Participation, stance and affect in the organization of activities. Discourse Soc 18(1):53-73

Gorini A, Gaggioli A, Riva G (2008) A second life for eHealth: prospects for the use of 3-D virtual worlds in clinical psychology. J Med Internet Res 10(3):e21

Gorman PJ, Meier AH, Krummel TM (2000) Computer-assisted training and learning in surgery. Comput Aided Surg 5(2):120-130

Gorsuch RL (1983) Factor analysis, 2nd edn. LEA, Hillsdale

Guerra JP, Pinto MM, Beato C (2015) Virtual reality-shows a new vision for tourism and heritage. Eur Sci J 11(9):49-54

Hain V, Hajtmanek R (2019) Industrial heritage education and user tracking in virtual reality. IntechOpen. https://doi.org/10.5772/ intechopen.90679. Available from: https://www.intechopen.com/ online-first/industrial-heritage-education-and-user-tracking-invirtual-reality

Hair JF, Anderson RE, Babin BJ, Black WC (2010) Multivariate data analysis: a global perspective, vol 7. Pearson, Upper Saddle River

Hammady R (2019) Virtual guidance using mixed reality in historical places and museums. (PhD PhD), Staffordshire University, Staffordshire Repositry. Accessed from http://eprints.staffs.ac. uk/5838/1/Thesis.pdf. Accessed 01 Jan 2020

Haugstvedt A-C, Krogstie J (2012) Mobile augmented reality for cultural heritage: a technology acceptance study. Paper presented at the 2012 IEEE international symposium on mixed and augmented reality (ISMAR)

Hayes AF (2012) PROCESS: A versatile computational tool for observed variable mediation, moderation, and conditional process modeling [Whitepaper]. Retrieved fromhttp://www.afhay es.com/public/process2012.pdf

Hayes A (2013) Introduction to mediation, moderation, and conditional process analysis a regression-based approach (Series Editor's Notes by Little, DT). In: The Guilford Press, London

Hayes AF (2017) Introduction to mediation, moderation, and conditional process analysis: a regression-based approach. Guilford Publications, New York

Hayes AF, Montoya AK, Rockwood NJ (2017) The analysis of mechanisms and their contingencies: PROCESS versus structural equation modeling. Australas Mark J (AMJ) 25(1):76-81

Hockett P, Ingleby T (2016) Augmented reality with HoloLens: experiential architectures embedded in the real world. arXiv preprint arXiv: 1610.04281

Hodge R, D'Souza W, Rivière GH (1979) The museum as a communicator: a semiotic analysis of the Western Australian Museum Aboriginal Gallery, Perth. Mus Int 31(4):251-267. https://doi. org/10.1111/j.1468-0033.1979.tb01899.x

Holloway JC (1981) The guided tour a sociological approach. Ann Tour Res 8(3):377-402

Hong J-C, Hwang M-Y, Hsu H-F, Wong W-T, Chen M-Y (2011) Applying the technology acceptance model in a study of the factors affecting usage of the Taiwan digital archives system. Comput Educ 57(3):2086-2094

Hooper-Greenhill E (1999) The educational role of the museum. Routledge, London

Hooper-Greenhill E (2013) Museums and their visitors. Routledge, London 
Horn AL (1980) A comparative study of two methods of conducting docent tours in art museums. Curator Mus J 23(2):105-117

Hughes K (1991) Tourist satisfaction: a guided "cultural" tour in North Queensland. Aust Psychol 26(3):166-171

Hughes CE, Smith E, Stapleton C, Hughes DE (2004) Augmenting museum experiences with mixed reality. Paper presented at the Proceedings of KSCE 2004

Hughes CE, Stapleton CB, Hughes DE, Smith EM (2005) Mixed reality in education, entertainment, and training. IEEE Comput Graph Appl 25(6):24-30

Hurter C, McDuff D (2017) Cardiolens: remote physiological monitoring in a mixed reality environment. Paper presented at the ACM SIGGRAPH 2017 emerging technologies

Jan D, Roque A, Leuski A, Morie J, Traum D (2009) A virtual tour guide for virtual worlds. Paper presented at the International workshop on intelligent virtual agents

Joachims T, Freitag D, Mitchell T (1997) Webwatcher: a tour guide for the world wide web. Paper presented at the IJCAI (1)

John B, Wickramasinghe N (2020) A review of mixed reality in Health Care. In: Wickramasinghe N, Bodendorf F (eds) Delivering superior health and wellness management with IoT and analytics. Springer, Berlin, pp 375-382

Jung T, tom Dieck MC, Lee H, Chung N (2016) Effects of virtual reality and augmented reality on visitor experiences in museum. In: Jung T, tom Dieck MC, Lee H, Chung $\mathrm{N}$ (eds) Information and communication technologies in tourism 2016. Springer, Berlin, pp 621-635

Karoulis A, Sylaiou S, White M (2006) Usability evaluation of a virtual museum interface. Informatica 17(3):363-380

Kateros S, Georgiou S, Papaefthymiou M, Papagiannakis G, Tsioumas M (2015) A comparison of gamified, immersive VR curation methods for enhanced presence and human-computer interaction in digital humanities. Int J Herit Digit Era 4(2):221-233

Keil J, Pujol L, Roussou M, Engelke T, Schmitt M, Bockholt U, Eleftheratou S (2013) A digital look at physical museum exhibits: designing personalized stories with handheld augmented reality in museums. Paper presented at the Digital heritage international Congress (DigitalHeritage), 2013

Kim S, Park E, Xu M (2020) Beyond the authentic taste: the tourist experience at a food museum restaurant. Tour Manag Perspect 36:100749

Knez EI, Wright AG (1970) The museum as a communications system: an assessment of Cameron's viewpoint. Curator Mus J 13(3):204-212. https://doi.org/10.1111/j.2151-6952.1970. tb00404.x

Koenig-Lewis N, Marquet M, Palmer A, Zhao AL (2015) Enjoyment and social influence: predicting mobile payment adoption. Serv Ind J 35(10):537-554

Kopp S, Gesellensetter L, Krämer NC, Wachsmuth I (2005) A conversational agent as museum guide-design and evaluation of a real-world application. Paper presented at the International workshop on intelligent virtual agents

Kress BC, Cummings WJ (2017) Towards the ultimate mixed reality experience: HoloLens display architecture choices. Paper presented at the SID symposium digest of technical papers

Lanir J, Kuflik T, Dim E, Wecker AJ, Stock O (2013) The influence of a location-aware mobile guide on museum visitors' behavior. Interact Comput 25(6):443-460

Lee H, Chung N, Jung T (2015) Examining the cultural differences in acceptance of mobile augmented reality: comparison of South Korea and Ireland. In: Tussyadiah I, Inversini A (eds) Information and communication technologies in tourism 2015. Springer, Berlin, pp 477-491

Lee K-F, Chen Y-L, Hsieh H-C, Chin K-Y (2017) Application of intuitive mixed reality interactive system to museum guide activity. Paper presented at the 2017 IEEE international conference on consumer electronics-Taiwan (ICCE-TW)

Lee H, Jung TH, tom Dieck MC, Chung N (2020) Experiencing immersive virtual reality in museums. Inf Manag Sci 57(5): 103229

Lepouras G (2004) Virtual museums for all: employing game technology for edutainment. Virtual Real J Virtual Real Soc 8(2):96106. https://doi.org/10.1007/s10055-004-0141-1

Leue M, Jung T (2014) A theoretical model of augmented reality acceptance. e-Rev Tour Res 5:1-6

Liarokapis F, Sylaiou S, Mountain DM (2008) Personalizing virtual and augmented reality for cultural heritage indoor and outdoor experiences. Paper presented at the VAST

Liu I-F, Chen MC, Sun YS, Wible D, Kuo C-H (2010) Extending the TAM model to explore the factors that affect intention to use an online learning community. Comput Educ 54(2):600-610

Loizides F, El Kater A, Terlikas C, Lanitis A, Michael D (2014) Presenting cypriot cultural heritage in virtual reality: a user evaluation. Paper presented at the Euro-Mediterranean conference

Luarn P, Lin H-H (2005) Toward an understanding of the behavioral intention to use mobile banking. Comput Hum Behav 21(6):873-891

Madsen JB, Madsen CB (2015) Handheld visual representation of a castle chapel ruin. J Comput Cult Herit 9(1):1-18

Magic Leap (2018) Magic Leap. Accessed from https://www.magic leap.com/. Accessed 10 Jan 2019

Mancini M (2000) Conducting tours: a practical guide. Nelson Education, Toronto

Microsoft (2015) Microsoft HoloLens. Accessed from https://www. microsoft.com/en-us/hololens/buy. Accessed 08 Mar 2018

Microsoft (2019) HoloLens 2 A new vision for computing. Accessed from https://www.microsoft.com/en-us/hololens/hardware. Accessed 10 Mar 2019

Mihelj M, Novak D, Beguš S (2014) Virtual reality technology and applications. Springer, Berlin

Milgram P, Takemura H, Utsumi A, Kishino F (1995) Augmented reality: a class of displays on the reality-virtuality continuum. In: Telemanipulator and telepresence technologies, vol 2351. International Society for Optics and Photonics, pp 282-292

Miyashita T, Meier P, Tachikawa T, Orlic S, Eble T, Scholz V, Gapel A, Gerl O, Arnaudov S, Lieberknecht S (2008, 15-18 Sept. 2008) An augmented reality museum guide. Paper presented at the 7th IEEE/ACM international symposium on mixed and augmented reality, 2008. ISMAR 2008

Munodawafa D (2008) Communication: concepts, practice and challenges. Health Educ Res 23(3):369-370. https://doi.org/10.1093/ her/cyn024

Muñoz A, Martí A (2020) New storytelling for archaeological museums based on augmented reality glasses. In: Hageneuer S (ed) Communicating the past in the digital age. Ubiquity Press, London. https://doi.org/10.5334/bch.g

Ng Giap Weng E, Parhizkar B, Chai Hsiao Ping L, Habibi La Shkari L (2011) Augmented reality for museum artifacts visualization. Int J Comput Sci Inf Secur 9(5):174-185

Owen R, Buhalis D, Pletinckx D (2005) Visitors' evaluations of ICTs used in cultural heritage. Paper presented at the Vast

Pietroszek K, Tyson A, Magalhaes FS, Barcenas CEM, Wand P (2019) Museum in your living room: recreating the peace corps experience in mixed reality. Paper presented at the 2019 IEEE Games, entertainment, media conference (GEM)

Pollalis C, Fahnbulleh W, Tynes J, Shaer O (2017) HoloMuse: enhancing engagement with archaeological artifacts through gesturebased interaction with holograms. Paper presented at the Proceedings of the tenth international conference on tangible, embedded, and embodied interaction 
Pollefeys M (2017) Second version of HoloLens HPU will incorporate AI coprocessor for implementing DNNs. Retrieved from: https ://www.microsoft.com/en-us/research/blog/second-version-holol ens-hpu-will-incorporate-ai-coprocessor-implementing-dnns/

Pond KL (1993) The professional guide: dynamics of tour guiding. Van Nostrand Reinhold, New York

Prasuethsut L (2016) Meta 2 first impressions: AR feels closer than ever. Accessed from https://www.wareable.com/ar/meta-2-revie w. Accessed 02 Apr 2017

Preacher KJ, Hayes AF (2008) Asymptotic and resampling strategies for assessing and comparing indirect effects in multiple mediator models. Behav Res Methods 40(3):879-891

Pujol L (2004) Archaeology, museums and virtual reality. Revista digital de humanidades, UOC. http://www.uoc.edu/humfil/articles/ eng/pujol0304/pujol0304.pdf

Pujol L, Roussou M, Poulou S, Balet O, Vayanou M, Ioannidis Y (2012) Personalizing interactive digital storytelling in archaeological museums: the CHESS project. Paper presented at the 40th Annual conference of computer applications and quantitative methods in archaeology. Amsterdam University Press

Rahimian FP, Seyedzadeh S, Oliver S, Rodriguez S, Dawood N (2020) On-demand monitoring of construction projects through a gamelike hybrid application of BIM and machine learning. Autom Constr 110:103012

Raptis GE, Fidas C, Avouris N (2017) Cultural heritage gaming: effects of human cognitive styles on players' performance and visual behavior. Paper presented at the Adjunct publication of the 25th conference on user modeling, adaptation and personalization

Raptis GE, Fidas C, Avouris N (2018) Effects of mixed-reality on players' behaviour and immersion in a cultural tourism game: a cognitive processing perspective. Int J Hum Comput Stud 114:69-79

Rasimah CMY, Ahmad A, Zaman HB (2011) Evaluation of user acceptance of mixed reality technology. Australas J Educ Technol 27(8):1369-1387

Rauschnabel PA, Ro YK (2016) Augmented reality smart glasses: an investigation of technology acceptance drivers. Int J Technol Mark 11(2):123-148

Rekimoto J, Ayatsuka Y (2000) CyberCode: designing augmented reality environments with visual tags. Paper presented at the Proceedings of DARE 2000 on Designing augmented reality environments, Elsinore, Denmark

Rift O (2020) Oculus Rift. Accessed from https://www.staffs.ac.uk/ news-archive/students-virtual-tutankhamen-tour-guide-bring s-museum-to-life-tcm4296023.jsp. Accessed 21 Feb 2020

Rosentraub MS, Joo M (2009) Tourism and economic development: which investments produce gains for regions? Tour Manag 30(5):759-770

Roussou M, Katifori A, Pujol L, Vayanou M, Rennick-Egglestone SJ (2013) A life of their own: museum visitor personas penetrating the design lifecycle of a mobile experience. Paper presented at the CHI '13 Extended abstracts on human factors in computing systems, Paris, France

Rubino I, Xhembulla J, Martina A, Bottino A, Malnati G (2013) Musa: using indoor positioning and navigation to enhance cultural experiences in a museum. Sensors 13(12):17445-17471

Ryffel M, Zünd F, Aksoy Y, Marra A, Nitti M, Aydın TO, Sumner B (2017) AR museum: a mobile augmented reality application for interactive painting recoloring. ACM Trans Graph (TOG) 36(2): 19

Rzayev R, Karaman G, Henze N, Schwind V (2019) Fostering virtual guide in exhibitions. Paper presented at the Proceedings of the 21st international conference on human-computer interaction with mobile devices and services

Sampaio AZ, Martins OP (2014) The application of virtual reality technology in the construction of bridge: the cantilever and incremental launching methods. Autom Constr 37:58-67
Schaper M-M, Santos M, Malinverni L, Berro JZ, Pares N (2018) Learning about the past through situatedness, embodied exploration and digital augmentation of cultural heritage sites. Int $\mathbf{J}$ Hum Comput Stud 114:36-50

Schmalstieg D, Wagner D (2007) Experiences with handheld augmented reality. Paper presented at the 6th IEEE and ACM International symposium on mixed and augmented reality, 2007. ISMAR 2007

Serubugo S, Skantárová D, Nielsen LK, Kraus M (2017) Comparison of wearable optical see-through and handheld devices as platform for an augmented reality museum guide. Paper presented at the VISIGRAPP (1: GRAPP)

Shang D, Wu W (2017) Understanding mobile shopping consumers' continuance intention. Ind Manag Data Syst 117(1):213-227

Shneiderman B, Plaisant C (2010) Designing the user interface: strategies for effective human-computer interaction. Pearson Education India, New Delhi

Siebert JN, Ehrler F, Gervaix A, Haddad K, Lacroix L, Schrurs P, Manzano S (2017) Adherence to AHA guidelines when adapted for augmented reality glasses for assisted pediatric cardiopulmonary resuscitation: a randomized controlled trial. J Med Internet Res 19(5):e183

Sparacino F (2002) The museum wearable: real-time sensor-driven understanding of visitors' interests for personalized visuallyaugmented museum experiences. In: Proceedings of museums and the web (MW2002)

Sugiura A, Kitama T, Toyoura M, Mao X (2019) The use of augmented reality technology in medical specimen museum tours. Anat Sci Educ 12(5):561-571

Sylaiou S, Mania K, Karoulis A, White M (2010) Exploring the relationship between presence and enjoyment in a virtual museum. Int J Hum Comput Stud 68(5):243-253

Sylaiou S, Kasapakis V, Dzardanova E, Gavalas D (2018) Leveraging mixed reality technologies to enhance museum visitor experiences. Paper presented at the 2018 International conference on intelligent systems (IS)

Sylaiou S, Kasapakis V, Dzardanova E, Gavalas D (2019) Assessment of virtual guides' credibility in virtual museum environments. Paper presented at the International conference on augmented reality, virtual reality and computer graphics

Tang YM, Au K, Lau HC, Ho GT, Wu C (2020) Evaluating the effectiveness of learning design with mixed reality (MR) in higher education. Virtual Real 24(4):1-11. https://doi.org/10.1007/ s10055-020-00427-9

Teo TS, Lim VK (1997) Usage patterns and perceptions of the internet: the gender gap. Equal Oppor Int 16(6/7):1-8

tom Dieck MC, Jung T, Han D-I, (2016) Mapping requirements for the wearable smart glasses augmented reality museum application. J Hosp Tour Technol 7(3):230-253

Trunfio M, Campana S, Magnelli A (2020) Measuring the impact of functional and experiential mixed reality elements on a museum visit. Curr Issues Tour 23(16):1990-2008. https://doi. org/10.1080/13683500.2019.1703914

Van Hage WR, Stash N, Wang Y, Aroyo L (2010) Finding your way through the rijksmuseum with an adaptive mobile museum guide. Paper presented at the Extended semantic web conference

Vlahakis V, Karigiannis J, Tsotros M, Gounaris M, Almeida L, Stricker D, Ioannidis N (2001) Archeoguide: first results of an augmented reality, mobile computing system in cultural heritage sites. Virtual Real Archeol Cult Herit 9:584993-585015

Vlahakis V, Ioannidis N, Karigiannis J, Tsotros M, Gounaris M, Stricker D, Gleue T, Daehne P, Almeida L (2002) Archeoguide: an augmented reality guide for archaeological sites. IEEE Comput Graph Appl 22(5):52-60 
Vo ML-H, Boettcher SE, Draschkow D (2019) Reading scenes: how scene grammar guides attention and aids perception in real-world environments. Curr Opin Psychol 29:205-210

Wagner D (2007) Handheld augmented reality. Ph.D., Citeseer

Wang N, Xia L (2019) Human-exhibition interaction (HEI) in designing exhibitions: a systematic literature review. Int J Hosp Manag 77:292-302

Warren T (2018) Acer's new Windows mixed reality headset has a detachable modular design. Accessed from https://www.theve rge.com/2018/8/29/17795120/acer-ojo-500-windows-mixed-reali ty-headset-features-price-release-date. Accessed 10 Jan 2018

Weiler B, Black R (2015) Tour guiding research: insights, issues and implications, vol 62. Channel View Publications, Bristol

Wojciechowski R, Cellary W (2013) Evaluation of learners' attitude toward learning in ARIES augmented reality environments. Comput Educ 68:570-585

Wooldridge JM (2015) Introductory econometrics: a modern approach. Nelson Education, Toronto

Xu Y, Stojanovic N, Stojanovic L, Cabrera A, Schuchert T (2012) An approach for using complex event processing for adaptive augmented reality in cultural heritage domain: experience report. Paper presented at the Proceedings of the 6th ACM international conference on distributed event-based systems, Berlin, Germany

Yalowitz SS, Bronnenkant K (2009) Timing and tracking: unlocking visitor behavior. Visit Stud 12(1):47-64

Yilmaz RM (2016) Educational magic toys developed with augmented reality technology for early childhood education. Comput Hum Behav 54:240-248

Zhang HQ, Chow I (2004) Application of importance-performance model in tour guides' performance: evidence from mainland Chinese outbound visitors in Hong Kong. Tour Manag 25(1):81-91

Zuk T, Carpendale MST, Glanzman WD (2005) Visualizing temporal uncertainty in 3D virtual reconstructions. Paper presented at the VAST

Publisher's Note Springer Nature remains neutral with regard to jurisdictional claims in published maps and institutional affiliations. 


\section{Terms and Conditions}

Springer Nature journal content, brought to you courtesy of Springer Nature Customer Service Center GmbH ("Springer Nature").

Springer Nature supports a reasonable amount of sharing of research papers by authors, subscribers and authorised users ("Users"), for smallscale personal, non-commercial use provided that all copyright, trade and service marks and other proprietary notices are maintained. By accessing, sharing, receiving or otherwise using the Springer Nature journal content you agree to these terms of use ("Terms"). For these purposes, Springer Nature considers academic use (by researchers and students) to be non-commercial.

These Terms are supplementary and will apply in addition to any applicable website terms and conditions, a relevant site licence or a personal subscription. These Terms will prevail over any conflict or ambiguity with regards to the relevant terms, a site licence or a personal subscription (to the extent of the conflict or ambiguity only). For Creative Commons-licensed articles, the terms of the Creative Commons license used will apply.

We collect and use personal data to provide access to the Springer Nature journal content. We may also use these personal data internally within ResearchGate and Springer Nature and as agreed share it, in an anonymised way, for purposes of tracking, analysis and reporting. We will not otherwise disclose your personal data outside the ResearchGate or the Springer Nature group of companies unless we have your permission as detailed in the Privacy Policy.

While Users may use the Springer Nature journal content for small scale, personal non-commercial use, it is important to note that Users may not:

1. use such content for the purpose of providing other users with access on a regular or large scale basis or as a means to circumvent access control;

2. use such content where to do so would be considered a criminal or statutory offence in any jurisdiction, or gives rise to civil liability, or is otherwise unlawful;

3. falsely or misleadingly imply or suggest endorsement, approval, sponsorship, or association unless explicitly agreed to by Springer Nature in writing;

4. use bots or other automated methods to access the content or redirect messages

5. override any security feature or exclusionary protocol; or

6. share the content in order to create substitute for Springer Nature products or services or a systematic database of Springer Nature journal content.

In line with the restriction against commercial use, Springer Nature does not permit the creation of a product or service that creates revenue, royalties, rent or income from our content or its inclusion as part of a paid for service or for other commercial gain. Springer Nature journal content cannot be used for inter-library loans and librarians may not upload Springer Nature journal content on a large scale into their, or any other, institutional repository.

These terms of use are reviewed regularly and may be amended at any time. Springer Nature is not obligated to publish any information or content on this website and may remove it or features or functionality at our sole discretion, at any time with or without notice. Springer Nature may revoke this licence to you at any time and remove access to any copies of the Springer Nature journal content which have been saved.

To the fullest extent permitted by law, Springer Nature makes no warranties, representations or guarantees to Users, either express or implied with respect to the Springer nature journal content and all parties disclaim and waive any implied warranties or warranties imposed by law, including merchantability or fitness for any particular purpose.

Please note that these rights do not automatically extend to content, data or other material published by Springer Nature that may be licensed from third parties.

If you would like to use or distribute our Springer Nature journal content to a wider audience or on a regular basis or in any other manner not expressly permitted by these Terms, please contact Springer Nature at

onlineservice@springernature.com 